\title{
Uncertainty assessment of equations of state with application to an organic Rankine cycle
}

Frutiger, Jerome; Bell, lan; O’Connell, John P.; Kroenlein, Kenneth; Abildskov, Jens; Sin, Gürkan

Published in:

Molecular Physics

Link to article, DOI:

$10.1080 / 00268976.2016 .1275856$

Publication date:

2017

Document Version

Peer reviewed version

Link back to DTU Orbit

Citation (APA):

Frutiger, J., Bell, I., O'Connell, J. P., Kroenlein, K., Abildskov, J., \& Sin, G. (2017). Uncertainty assessment of equations of state with application to an organic Rankine cycle. Molecular Physics, 115(9-12), 1235-1244. https://doi.org/10.1080/00268976.2016.1275856

\section{General rights}

Copyright and moral rights for the publications made accessible in the public portal are retained by the authors and/or other copyright owners and it is a condition of accessing publications that users recognise and abide by the legal requirements associated with these rights.

- Users may download and print one copy of any publication from the public portal for the purpose of private study or research.

- You may not further distribute the material or use it for any profit-making activity or commercial gain

- You may freely distribute the URL identifying the publication in the public portal 


\section{Uncertainty Assessment of Equations of State with Application to an Organic Rankine Cycle ${ }^{1}$}

Jérôme Frutiger ${ }^{a}$, Ian Bell ${ }^{b}$, John P. O’Connell ${ }^{c}$, Kenneth Kroenlein ${ }^{b}$, Jens Abildskov ${ }^{a}$, Gürkan Sin ${ }^{a^{*}}$

a) CAPEC-PROCESS Research Center, Department of Chemical and Biochemical Engineering, Technical University of Denmark (DTU), Kgs. Lyngby, Denmark

b) Applied Chemicals and Materials Division, National Institute of Standards and Technology, Boulder, United States of America

c) Department of Chemical Engineering, University of Virginia, Charlottesville, United States of America

*corresponding author: Gürkan Sin, gsi@kt.dtu.dk, Tel.: +45 45252806

\section{Post-print}

This is a post-print of the article published online on the 27th of January 2017 in Molecular Physics. The publisher's version is available at: http://dx.doi.org/10.1080/00268976.2016.1275856

\section{To cite this article}

Jérôme Frutiger, Ian Bell, John P. O'Connell, Kenneth Kroenlein, Jens Abildskov \& Gürkan Sin (2017): Uncertainty assessment of equations of state with application to an organic Rankine cycle, Molecular Physics, DOI: 10.1080/00268976.2016.1275856

\section{Funding}

This work was supported by the Danish Council for Strategic Research in Sustainable Energy and Environment under the THERMCYC project.

${ }^{1}$ Commercial equipment, instruments, or materials are identified only in order to adequately specify certain procedures. In no case does such identification imply recommendation or endorsement by the National Institute of Standards and Technology, nor does it imply that the products identified are necessarily the best available for the purpose. Contribution of the National Institute of Standards and Technology, not subject to copyright in the US 


\section{Uncertainty Assessment of Equations of State with Application to an Organic Rankine Cycle}

Evaluations of equations of state (EoS) should include uncertainty. This study presents a generic method to analyse EoS from a detailed uncertainty analysis of the mathematical form and the data used to obtain EoS parameter values. The method is illustrated by comparison of Soave-Redlich- Kwong (SRK) cubic EoS with perturbed-chain statistical associating fluid theory (PC-SAFT) EoS for an organic Rankine cycle (ORC) for heat recovery to power from the exhaust gas of a marine diesel engine using cyclopentane as working fluid. Uncertainties of the EoS input parameters including their corresponding correlation structure, are quantified from experimental measurements using a bootstrap method. Variance-based sensitivity analysis is used to compare the uncertainties from the departure function and the ideal-gas contribution. A Monte Carlo procedure propagates fluid parameter input uncertainty onto the model outputs. Uncertainties in the departure function (SRK or PC-SAFT EoS) dominate the total uncertainties of the ORC model output. For this application and working fluid, SRK EoS has less predictive uncertainty in the process model output than does PC-SAFT EoS, though it cannot be determined if this is due to differences in the data for parameter estimation or in the mathematical form of the EoS or both.

Keywords: uncertainty analysis, parameter correlation, cubic EoS, PC-SAFT, organic Rankine cycle 


\section{Introduction}

Low-temperature Organic Rankine Cycles (ORC) systems are used to produce electrical power from waste heat (e.g. in marine diesel engine applications [1]). The basic ORC is a power cycle consisting of a pump, an evaporator, an expansion machine and a condenser [2], with a working fluid continuously circulating through the units [3]. In order to evaluate and test promising fluid candidates for a cycle, an equation of state (EoS) is commonly used. In recent years, there has been significant interest in the selection of working fluids for ORCs and optimizing their application.

Screening techniques and multi-criteria database searches [3] as well as Computer Aided Molecular Design (CAMD) [4] have been extensively applied to find appropriate working fluids for ORCs. The reviews by Bao et al. [5] on fluid selection, and by Linke et al. [6] on molecular fluid design, reference studies concerning working fluids for ORCs.

Several families of EoS have been used for ORC working fluid design and selection studies. Forms of the Helmholtz EoS (as implemented in the well-established REFPROP library [7], or alternatively in the CoolProp library [8]) have been used. The works of Wang et al. [9], Chys et al. [10], Andreasen et al. [11], Zhai et al. [12], Luo et al. [13], Rödder et al. [14], Hærvig et al. [15], and Xu et al. [16] are examples of screening fluids using high-accuracy fundamental EoS of this form. While libraries like REFPROP or CoolProp implement the most accurate equations of state available in the literature, only a limited number of fluids have been treated with these EoS, preventing wide-range database searches or molecular design studies. However, the rapid development of novel high-performance working fluids that satisfy rigorous safety requirements with low environmental impact [17][18] demand such capabilities.

Cubic EoS, such as Peng-Robinson (PR) [19], Soave-Redlich-Kwong (SRK) [20], and Predictive Soave-Redlich-Kwong (PSRK) [21], have also been used for calculating the thermodynamic properties of ORC working fluids. PR and SRK are particularly convenient for working fluid design studies, because they only require three fluid-specific input properties to their EoS: the critical temperature, $T_{c}$, the critical pressure, $P_{c}$, and the acentric factor, $\omega$. The PR EoS [19] was implemented into 
molecular design frameworks for working fluids by Papadopoulos et al. [4], [22]. Also, Drescher et al. [23], Brown et al. [24], Liu et al. [25] and Frutiger et al. [26] used the PR EoS to screen a large number of working fluids, while Roskosch et al. [27] implemented the PR EoS into their reverse engineering methodology for fluid selection. Finally, Sanchez et al. [28] predicted the thermodynamic properties of the working fluids in their cycle application with SRK, while Molina-Thierry et al. [29] chose PSRK for their CAMD framework.

In addition, Perturbed-Chain Statistical Associating Fluid Theory (PC-SAFT) [30] has also been used for working fluid properties due to its relatively small number of adjustable parameters that are conceptually related to molecular characteristics. Thus, Lai et al. [3][31] applied PC-SAFT to a working fluid analysis of an ORC and a SAFTtype EoS was also used for fluid modeling in the work of Oyeniyi et al. [32]. Most recently PC-SAFT was also implemented in a molecular design framework for ORC working fluids by Lampe et al. [33].

Additional EoS models have been reported in the literature for prediction of thermophysical properties of working fluids: e.g. BACKONE EoS [34], Martin-Hou EoS [35], and Patel-Teja EoS [36]. However, it seems that extended database screening and molecular design for novel fluids is most often performed with either cubic forms, due to their simple structure, or the PC-SAFT EoS with a more complex form but a limited number of parameters.

For ORC applications, an EoS is commonly selected based on goodness-of-fits to data, range of availability of fluid data, limited complexity of model formulation as related to numerical complexity [37], and/or ease of implementation. For example, Kumar et al. [38] compared the results of thermodynamic properties obtained from a variety of EoS for gas turbine applications to those from a complex, but highly accurate multi-parameter Helmholtz energy-explicit EoS [39], to determine which simple EOS would best describe compressor efficiency.

In all of these works, when comparisons have been made among different models, there was little concern shown about variations in the number of parameters and their origin from experiment. Analyses were based on the typical application approaches 
of users who normally select models based on simplicity of form and calculation versus capability to replicate particular experimental data.

However, an additional criterion for the choice of an EoS, that seems not to have been explored thoroughly, is the influence of the uncertainty of the fluid-specific parameters of the EoS on the ORC model output. It should be expected that lower uncertainties would provide more reliable process designs from models.

Experimental property data (e.g. critical properties, saturation pressures, and liquid densities) have been normally used to determine parameters of an EoS. These data have associated uncertainties arising from the measurements [40] and how the model incorporates the values [41]. We believe that these property uncertainties should be taken into account when applying an EoS to processes such as ORC [42].

We distinguish the difference between accuracy and uncertainty in the context of computational models for property prediction or process design. Accuracy is the difference between the output predicted by the model and a particular set of experimental measurements of the property or process output. Uncertainty is the range of statistically possible outcomes of the model (usually assumed to be a normal distribution and reported with $95 \%$ confidence). The sources of uncertainty are: 1) the model parameters representing incomplete knowledge of fixed values (input uncertainty); 2) the mathematical formulation of the model only approximating nature (structural uncertainty); and 3) stochastic components of a process simulation (stochastic uncertainty) [42]. The current study focuses on uncertainties of the parameters of the EoS and their impacts on the uncertainties of ORC process calculations.

In non-linear regression theory, the uncertainties of parameters are defined by the parameter covariance matrix, which should be generated by the developers of the models after parameter optimization. However, developers often do not provide the covariance matrix for EoS studies.

In the preliminary phase of conceptual process design, such as for a new ORC, experimental temperature and pressure data at the process states are often unavailable. Thus, model accuracy and the complementary uncertainty are the only means available to assess potential errors in process design and simulation. 
Feistel et al. [43] analyzed the uncertainties of empirical reference EoS. They used generalized least squares for parameter regression and propagated the covariance of the input data uncertainties into the calculated values, and into the fitted value covariance matrix. In this way, estimates of the uncertainties of the derived quantities (e.g., the second and third virial coefficients of water) were provided.

Frutiger et al. [26] recently presented a methodology to propagate and quantify the impact of parameter uncertainty on an ORC model output, using the PR EoS for thermodynamic properties. A Monte Carlo method was used to propagate the uncertainty of the fluid-specific EoS parameters to the ORC model output. This provided distributions of the cycle power output resulting from fluid property uncertainties. The uncertainties of fluid properties were assumed to be known a priori, based on information reported in databases or from information reported in predictive models of pure component properties (e.g., the study of Hukkerikar et al. [41]). Several candidate fluids were compared and ranked according to ORC model output uncertainties. This approach allowed the use of uncertainty as an additional dimension in the fluid selection process [26].

A comprehensive methodology to include assessment of model parameter uncertainty based on experimental data is needed. Toward this end, we investigate the following items:

- Quantification of uncertainty and the correlation structure of input properties and parameters based on experimental data

- Sensitivity analysis of the different contributions to the uncertainty of a given EoS, such as ideal-gas versus departure function contributions

- Comparisons of different types of EoS based on fluid-specific uncertainties propagated to the model output of an ORC

- Uncertainty analysis to complement accuracy in selecting an EoS for a given application

We apply a Monte Carlo method for analysis of the commonly used types of EoS in the field of working fluids: cubic (i.e., SRK) and PC-SAFT. Apart from the work of Feistel et al. [43], we do not know of any systematic assessments of EoS in terms of 
uncertainty propagation. We apply this generalized procedure to an ORC application for power generation using a low-temperature heat source of exhaust gas from a marine diesel engine.

The paper is organized as follows: (i) the overall methodology is outlined; (ii) cubic EoS and PC-SAFT, as well as the ORC model formulation, are briefly presented; (iii) the method to obtain the input uncertainties by quantifying experimental error is shown; (iv) the Monte Carlo procedure used to perform uncertainty analysis and variance-based sensitivity analysis is explained; (v) the results of the uncertainty analysis of cubic and PC-SAFT EoS are compared. 


\section{Method and Tools}

The methodology involves the set of steps given in Table 1.

Table 1. Overview of the methodology.

\section{Step 1 Formulation of EoS and fluid selection}

Step 2 Organic Rankine cycle (ORC) process model formulation and optimization of process parameters

Step 3

Quantification of uncertainties in fluid-specific EoS parameters based on experimental data

Step 3.1

Quantification of uncertainty for critical properties and acentric factor for cubic SRK EoS

Step 3.2 Quantification of uncertainty for parameters of PC-SAFT EoS

Step 3.3 Quantification of uncertainty for ideal-gas heat capacity parameters

Step 4

Monte Carlo procedure for input uncertainty propagation to ORC process model output of cubic SRK and PC-SAFT EoS

Step 4.1 Specification of fluid property and parameter input uncertainties

Step 4.2 Sampling of property and parameter search spaces

Step 4.3 Evaluation of ORC model for each property and parameter sample

\section{Step 5 Variance-based sensitivity analysis and EoS selection}

Step 5.1 Calculation of variance-based sensitivity measures

Step 5.2 Analysis and selection of EoS based on accuracy and uncertainty

\section{Step 1: Formulation of EoS and fluid selection}

Models of process cycles require evaluation of thermodynamic properties (e.g. enthalpies, entropies, fugacities). The enthalpy, $h$, and entropy, $s$, have an ideal contribution (i.e. the ideal-gas enthalpy and entropy) and a nonideal gas contribution (departure function, [47]) for the difference between ideal- and real-fluid behaviors: 


$$
\begin{gathered}
h(P, T)=h^{\mathrm{ref}}+h(T)^{\mathrm{ideal}}+h(P, T)^{\mathrm{dep}} \\
s(P, T)=s^{\text {ref }}+s(P, T)^{\mathrm{ideal}}+s(P, T)^{\mathrm{dep}}
\end{gathered}
$$

where $P$ is the pressure and $T$ the temperature. The reference enthalpy and entropy, $h^{\text {ref }}$ and $s^{\text {ref }}$, are those defined at the reference state of $T^{\mathrm{ref}}=273.15 \mathrm{~K}$ and $P^{\mathrm{ref}}=1 \mathrm{~atm}$. The enthalpy and entropy of the ideal gas at $T$, are $h(T)^{\text {ideal }}$ and $s(P, T)^{\text {ideal }}$, while $h(P, T)^{\text {dep }}$ and $s(P, T)^{\text {dep }}$ are the respective departure functions. Fugacities can be directly calculated from EoS departure functions, but also more generally from derivatives of the Helmholtz energy [37][44]. Here we use departure functions from two different EoS for uncertainty analysis: the cubic Soave-Redlich-Kwong (SRK) EoS and the non-associating Perturbed Chain Statistical Association Fluid Theory (PC-SAFT) EoS. The equations differ in mathematical form. A detailed description of the physical background of both cubic and SAFT-type EoS can be found in the work of Kontogeorgis et al. [45].

The SRK EoS originates from Van der Waals-type EoS, in particular the Redlich-Kwong EoS [46]. The underlying principle of van der Waals EoS is to improve upon the ideal-gas law by including attractive and repulsive terms. Soave [20] extended the Redlich-Kwong EoS, by making the $a$ parameter a function of temperature and the acentric factor, $\omega$,

$$
P=\frac{R T}{V_{\mathrm{m}}-b}-\frac{a \alpha}{V_{\mathrm{m}} \cdot\left(V_{\mathrm{m}}-b\right)}
$$

In Eq. (3) $R$ is the universal gas constant, $T$ is the absolute temperature, $P$ is the absolute pressure and $V_{\mathrm{m}}$ is the molar volume. Soave defined the $\alpha$ function as:

$$
\begin{gathered}
a=\frac{0.42747 R^{2} T_{\mathrm{c}}^{2}}{P_{\mathrm{c}}} \\
b=\frac{0.08664 R T_{\mathrm{c}}}{P_{\mathrm{c}}} \\
\alpha=\left(1+\left(0.480+1.574 \cdot \omega-0.176 \cdot \omega^{2}\right) \cdot\left(1-\sqrt{T_{\mathrm{r}}}\right)\right)^{2}
\end{gathered}
$$




$$
T_{\mathrm{r}}=\frac{T}{T_{\mathrm{r}}}
$$

Eq. (7) defines $T_{\mathrm{r}}$ as used in Eq. (6). Thus, knowing the three primary properties $T_{\mathrm{c}}, P_{\mathrm{c}}$ and $\omega$ for a fluid, its departure thermodynamic properties can be calculated from the SRK EoS. The formulations for fugacity, enthalpy, and entropy can be found in Soave [20] and Poling, et al. [47]. The Peng-Robinson EoS [19] is a cubic model closely related to SRK and performs similarly for any given process model. The computational implementation of SRK EoS was done by Liu et. al [25]. The uncertainty propagation of Peng-Robinson EoS has been investigated by Frutiger et al. [26]

Statistical Associating Fluid Theory (SAFT), is based on a statistical thermodynamic theory for fluids with a repulsive core and directional short-range attractive sites. Economou [48] has reviewed the development of SAFT-type EoS. The Perturbed chain-SAFT (PC-SAFT) EoS for non-associating fluids [30] treats molecules as chains of spherical elements with a pair potential. A temperature-dependent hard sphere diameter $d(T)$ for the segments is used to describe the soft repulsion of molecules [49]

$$
d(T)=\sigma[1-0.12 \cdot \exp (-3 \epsilon /(k T))]
$$

In Eq. (8) $\sigma$ is the segment diameter (size parameter), $\epsilon$ is the depth of the intersegment molecular pair potential (energy parameter), and $k$ is the Boltzmann constant.

In the PC-SAFT EoS, thermodynamic properties become a sum of a hard chain contribution and perturbation terms according to the second-order perturbation theory of Barker and Henderson [49]. Thus, the nonideal Helmholtz energy, $A_{\text {res }}$ of a system of $N$ chain molecules has the form

$$
\frac{A_{\mathrm{res}}}{N k T}=\frac{A_{\mathrm{hc}}}{N k T}+\frac{A_{\mathrm{disp}}}{N k T}
$$

where $A_{\mathrm{hc}}$ is the hard-chain reference contribution and $A_{\text {disp }}$ is the dispersion contribution. The detailed expressions for all thermodynamic properties can be found in the work of Gross et al. [30]. In addition to $\sigma$, and $\epsilon$, a chain length parameter, $m$, is 
included. The energy parameter is generally reported as $\epsilon / k$. The computational implementation of PC-SAFT EoS is based on the work of Gross et al. [30] and of Fakouri Baygi et al. [50].

Both SRK and PC-SAFT require three fluid-specific parameters. However, SRK uses properties ( $T_{\mathrm{C}}, P_{\mathrm{c}}$ and $\left.\omega\right)$, which can be measured. Typically $T_{\mathrm{c}}$ is determined directly, while $P_{\mathrm{c}}$ and $\omega$ are obtained from vapor pressure curves [51]. The PC-SAFT parameters $(\sigma, \epsilon / k$ and $m$ ) must be obtained by fitting the EoS to a combination of property data, e.g., vapor pressure and (liquid) density data as functions of temperature [30]. Experimental data used to determine the EoS parameters are often subject to nonnegligible uncertainties [40], so this needs to be included in any uncertainty analysis.

The ideal-gas enthalpy and entropy terms are obtained by integrating a temperature-dependent ideal-gas heat capacity function, $c_{\mathrm{p}}(T)$, with parameters obtained from fitting thermal or spectroscopic measurements combined with molecular theory. We use the Aly-Lee ideal-gas heat capacity form with five compound-specific input parameters $(A, B, C, D, E)[52]$.

$$
c_{\mathrm{p}}(T)=A+B \cdot\left[\frac{\frac{C}{T}}{\sinh \left(\frac{C}{T}\right)}\right]^{2}+D \cdot\left[\frac{\frac{E}{T}}{\cosh \left(\frac{E}{T}\right)}\right]^{2}
$$

For the present fluid, cyclopentane, fluid property data were obtained from NIST ThermoData Engine [53][54] for $T_{c}, P_{c}, \omega$; the DIPPR 801 AIChE database [55] for $A$, $B, C, D, E$; and from Gross and Sadowski [30] for $\sigma, \epsilon / k$, and $m$.

Natural refrigerants, such as cyclopentane show promising performance in Organic Rankine cycles, have no ozone depletion potential, and possess much lower global warming potential compared to fluorinated and chlorinated compounds [56] some of which are being phased-out in Europe [17]. The disadvantage of natural refrigerants is that many, including cyclopentane, are highly flammable. The input property and parameter data of cyclopentane are listed in Table 2. 
Table 2. EoS input property and parameter data for cyclopentane.

\begin{tabular}{|c|c|c|c|c|c|c|}
\hline \multirow{2}{*}{$\begin{array}{l}\text { Input properties } \\
\text { to cubic SRK }\end{array}$} & $\begin{array}{c}T_{\mathrm{C}} \\
{[\mathrm{K}]}\end{array}$ & $\begin{array}{c}P_{\mathrm{C}} \\
{[\mathrm{Pa}]}\end{array}$ & $\begin{array}{c}\omega \\
{[-]}\end{array}$ & \multicolumn{3}{|c|}{ Ref. } \\
\hline & 511.7 & $4.5110^{6}$ & 0.19 & \multicolumn{3}{|c|}{ [67] } \\
\hline \multirow{2}{*}{$\begin{array}{l}\text { Input parameters } \\
\text { to PC-SAFT }\end{array}$} & $\begin{array}{c}\sigma \\
{[\AA]}\end{array}$ & $\begin{array}{c}\epsilon / k \\
{[\mathrm{~J} / \mathrm{K}]}\end{array}$ & $\begin{array}{l}\mathrm{m} \\
{[-]}\end{array}$ & \multicolumn{3}{|c|}{ Ref. } \\
\hline & 3.7114 & 265.83 & 2.3655 & \multicolumn{3}{|c|}{ [30] } \\
\hline \multirow{2}{*}{$\begin{array}{l}\text { Input parameters } \\
\text { to Aly-Lee heat } \\
\text { capacity }\end{array}$} & $\begin{array}{c}A \\
{[\mathrm{~J} /(\mathrm{kmol} \cdot \mathrm{K})]}\end{array}$ & $\begin{array}{c}B \\
{[\mathrm{~J} /(\mathrm{kmol} \cdot \mathrm{K})]}\end{array}$ & $\begin{array}{c}C \\
{[\mathrm{~K}]}\end{array}$ & $\begin{array}{c}D \\
{[\mathrm{~J} /(\mathrm{kmol} \cdot \mathrm{K})]}\end{array}$ & $\begin{array}{c}E \\
{[\mathrm{~K}]}\end{array}$ & Ref. \\
\hline & 41600 & 301400 & 1462 & 180950 & 669 & [55] \\
\hline
\end{tabular}

We have compared the accuracy of SRK and PC-SAFT for cyclopentane with a reference EoS [57]. For the calculation of saturation pressure as function of temperature from $290 \mathrm{~K}$ to $510 \mathrm{~K}$, the PC-SAFT EoS had an average relative error of $0.05 \%$, while SRK had $0.20 \%$. Hence, although both agree well, the PC-SAFT EoS was found to be more accurate, at least for saturation pressure. However, this is not unexpected, because PC-SAFT parameters were fitted to vapour pressure data. We have not compared the results for liquid densities.

\section{Step 2: Organic Rankine cycle (ORC) model formulation and optimization of process parameters}

The Organic Rankine Cycle (ORC) process of this study is a waste heat recovery (WHR) system for electricity production on a large container ship [58]. The process model is based on the work of Andreasen et al. [59] and Frutiger et al. [26]. Frutiger et al. provided a detailed description of the process model.

In the ORC process, the exhaust gas of an on-board MAN diesel engine provides the high temperature heat, with the low temperature heat rejected to sea water [60]. The ORC system has five main components: pump, evaporator (preheater, evaporator and 
superheater), turbine, condenser, and recuperator (see Figure 1). The working fluid is saturated liquid at low pressure at the pump inlet (state 1). The pump pressurizes it to state 2. It is then directed through the recuperator, to heat up the stream to state 3 . It enters the evaporator for preheating to the saturated liquid state 4, evaporating and (optionally) superheating to state 5. In the turbine, the hot pressurized vapor expands to state 6 , producing mechanical power which is converted to electricity by a generator connected to the turbine. The low pressure vapor condenses in the recuperator (state 7) and in the condenser completes the cycle to state 1. 


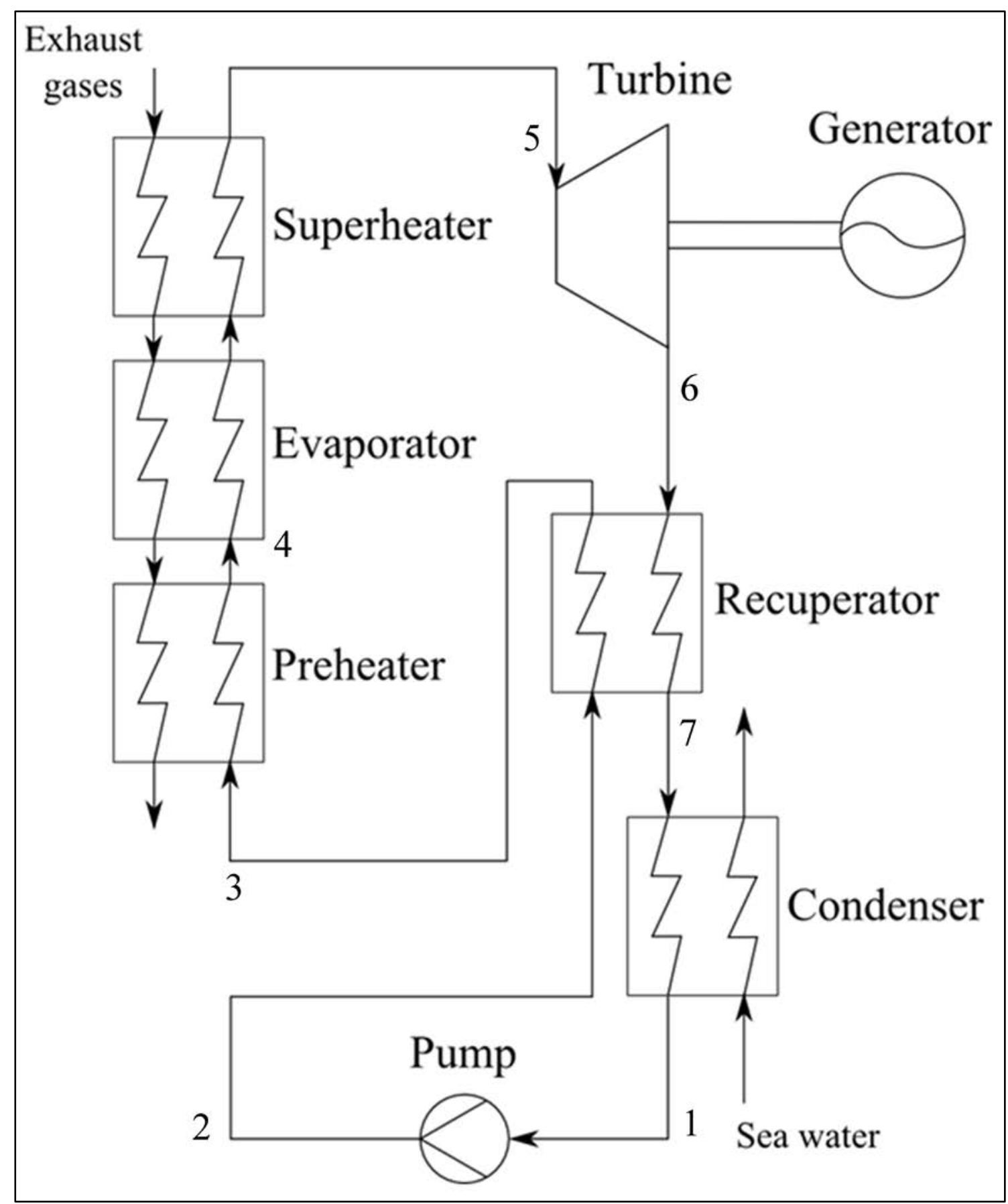

Figure 1. An overview over the ORC process adapted from Andreasen et al. [59].

The process data were provided by MAN Diesel and Turbo [61]. The modelling constraints of the process and of the hot fluid are summarized in Table 3. Engine exhaust gas (i.e. air), at a temperature of $222{ }^{\circ} \mathrm{C}$ and mass flow rate of $95.4 \mathrm{~kg} / \mathrm{s}$, serves as the heat source. Further constraints are: 1) the exhaust gas (air) outlet temperature is 
limited to $160{ }^{\circ} \mathrm{C}$; 2) at the turbine inlet and outlet, as well as at the saturated liquid point, the minimum temperature difference between the hot and cold streams in the evaporator is set to $10 \mathrm{~K}$; 3) the whole cycle operates at subcritical conditions with the maximum evaporator pressure limited to $0.95 P_{c}$.

Table 3. Constraints for the ORC process model.

\begin{tabular}{l|r}
\hline Process parameter & Value \\
\hline Exhaust gas (hot fluid) inlet temperature & $222^{\circ} \mathrm{C}$ \\
Exhaust gas (hot fluid) outlet temperature & $160{ }^{\circ} \mathrm{C}$ \\
Exhaust gas (hot fluid) mass flow rate & $95.4 \mathrm{~kg} / \mathrm{s}$ \\
Exhaust gas (hot fluid) pressure & $0.11 \mathrm{MPa}$ \\
Condensation temperature & $30{ }^{\circ} \mathrm{C}$ \\
Condenser outlet vapor quality (state 1) & 0 \\
Pump isentropic efficiency & 0.8 \\
Minimum evaporater temperature difference & $10 \mathrm{~K}$ \\
Minimum recuperator temperature difference & $10 \mathrm{~K}$ \\
Turbine isentropic efficiency & 0.8 \\
Minimum turbine outlet vapor quality (state 6) & 1 \\
\hline
\end{tabular}

The assumptions used in the numerical modeling are: No pressure losses in piping or heat exchangers, no heat loss from the system, and steady state operation [26].

The outputs from the ORC process model are the net power output $W_{\mathrm{NET}}$, the mass flow $\dot{m}_{\mathrm{wf}}$ of the working fluid, and state variables such as pressures $P_{i}$, temperatures $T_{i}$, entropies $s_{i}$, and enthalpies $h_{i}$, (see Figure 1). The net power output $W_{\text {NET }}$ (i.e. the difference between turbine power production and pump power consumption) can be calculated from Eq.(11).

$$
W_{\mathrm{NET}}=W_{\mathrm{Turb}}-W_{\mathrm{Pump}}
$$




$$
\begin{gathered}
W_{\text {Turb }}=\dot{m}_{\mathrm{wf}}\left(h_{5}-h_{6}\right) \\
W_{\text {Pump }}=\dot{m}_{\mathrm{wf}}\left(h_{2}-h_{1}\right)
\end{gathered}
$$

where $h_{i}$ is the enthalpy at state $i$ (see Figure 1) and $\dot{m}_{\mathrm{wf}}$ is the mass flow rate of the working fluid, given by energy balances over the evaporator, preheater, and superheater:

$$
\dot{m}_{\mathrm{wf}}=\dot{m}_{\text {air }} \cdot \frac{c_{\mathrm{p} \text { air }}\left(T_{\text {air in }}-T_{\text {air out }}\right)}{h_{5}-h_{3}}
$$

In Eq. (14) $c_{\mathrm{p} \text { air }}$ is the heat capacity of the hot air (exhaust gas), which is assumed constant; $T_{\text {air in }}$, the temperature of the air flowing into the ORC (i.e. the output temperature of the diesel engine); $T_{\text {air out }}$, the temperature of air leaving the ORC; and $\dot{m}_{\text {air }}$, the exhaust gas mass flow rate.

The thermal efficiency of the cycle can be expressed as

$$
\eta_{\text {therm }}=\frac{W_{\mathrm{NET}}}{\dot{m}_{\text {air }} c_{\mathrm{p} \text { air }}\left(T_{\text {air in }}-T_{\text {air out }}\right)}
$$

A degrees of freedom analysis of the cycle suggests that two process variables can be solved for and optimized. We choose the turbine inlet pressure, $P_{5}$, and the turbine inlet temperature, $T_{5}$. The optimal process conditions were identified by performing particle swarm optimization [62] for cyclopentane.

\section{Step 3: Quantification of uncertainty of fluid-specific EoS parameters based on experimental data}

The goal of this step is to obtain the uncertainties and the correlation matrix of the cubic SRK input parameters $\left(T_{c}, P_{c}, \omega\right)$, the PC-SAFT parameters $(\sigma, \epsilon / k, m)$, and the Aly-Lee heat capacity parameters $(A, B, C, D, E)$. The quantification is based on the thermodynamic property data. In order to achieve this, the bootstrap method described by Efron [63] is used.

The bootstrap method attempts to quantify the underlying distributions of residual errors commonly defined in statistical contexts as the differences between the 
experimental data and their corresponding model calculations. This should not be confused with the thermodynamic term "residual function", which is related to the thermodynamic departure function [47]. The residual errors are used to obtain synthetic data sets for parameter estimation by using random sampling with replacement. This procedure is a form of nonlinear propagation of measurement errors to errors as parameter estimators. It is different from non-linear regression theory which relies on asymptotic approximation of the parameter covariance matrix that requires calculation of the jacobian matrix and the assumption that measurement errors are independently identically distributed and follow normal distribution with means equal to zero [64]. In many practical application, this assumption is rarely met (see for instance the residual plots in Hukkerikar et al. [41]. Therefore, the bootstrap method that works with the actual distribution of residuals is more appropriate to use in such situations. The method has previously been applied to the development of group contribution methods by Frutiger et al. [65].

We now outline the bootstrap method [63]. A generic model $F([\theta])$ with parameters $[\theta]$ to predict variable $y^{\text {pred }}$ is given by

$$
y^{\text {pred }}=F([\theta])
$$

The goal is to fit the model parameters giving $y^{\text {pred }}$ to the experimental data set, $y^{\exp }$, of $N_{\text {data }}$ data points, obtaining the parameter estimates $\theta^{*}$ and their corresponding uncertainties.

(1) A reference parameter estimation is made using a non-linear least squares method to obtain the first parameter estimates $\left[\theta^{*}\right]$ :

(2) The residual error for each data point is defined as:

$$
\hat{\epsilon}_{i}=\left(y_{i}^{\text {exp }}-y_{i}^{\text {pred }}\right)
$$

Each residual error $\hat{\epsilon}_{i}$ has equal probability of occurring, with a probability of $1 /$ $N_{\text {data }}$. 
(3) New synthetic data sets are produced via the bootstrap method. Random sample replacements are made of residual errors $\hat{\epsilon}$ to generate $k$ synthetic data sets $\left(y^{*}(1) ; y^{*}(2), \ldots, y^{*}(k)\right)$, each with $N_{\text {data }}$ data points. In practice, this bootstrap method simply samples errors and adds them randomly to the estimated properties in the reference step above (i.e., it rearranges the errors):

$$
y_{i}(k)^{*}=y_{i}^{\text {pred }}+\hat{\epsilon}_{i} \quad \hat{\epsilon}_{i} \in \hat{F}(\epsilon)
$$

where $i$ (from 1 to $N_{\text {data }}$ ) stands for the index of measured data and $\hat{F}$ is the probability function of $\hat{\epsilon}$ (with probability of realization of $1 / N_{\text {data }}$ for all $\hat{\epsilon}$ )

(4) The least squares parameter estimation is repeated using each synthetic data set $y^{*}(k)$, which results in a new set of estimated parameters $\theta^{*}(k)$ and a new set of predicted values, $y^{\text {pred* }}(k)$. In this way, distributions of the parameters as well as of the predicted values are obtained for representing the uncertainty in the estimated values.

(5) Inference statistics can be used to estimate the mean and standard deviation (SD) of the distributions:

$$
S D\left(\theta^{*}\right)=\sqrt{\frac{1}{N_{\text {data }}-1} \sum_{k=1}^{n}\left(\theta^{*}(k)-\mu_{\theta^{*}}\right)^{2}}
$$

In Eq. (20), $\theta^{*}(k)$ are the estimated parameters from the $k^{\text {th }}$ synthetic data set and $\mu_{\theta^{*}}$ is its mean value, which is given by

$$
\mu_{\theta^{*}}=\frac{1}{N_{\text {data }}} \sum_{k=1}^{n} \theta^{*}(k)
$$

The obtained standard deviations are estimates of the parameter uncertainties.

Another important feature of the bootstrap method is that it allows estimation of the correlation structure between the errors of the different parameters (e.g. for PCSAFT: the correlation structure between the residual errors associated with values of $\sigma$, $\epsilon / k$ and $m$ ). It is essential for the uncertainty analysis (Step 4 of the methodology) to 
preserve the original correlation structure, to avoid the output variance calculation being incorrect [66].

Quantification of uncertainty for critical properties and acentric factor for cubic SRK EOS

For many hydrocarbons, $T_{\mathrm{c}}$ has been measured experimentally [47][67]. Hence, its measurement uncertainty serves as input uncertainty for the EoS in this study. However, $P_{c}$ and $\omega$ are often obtained from vapor pressure curves as described by Patel and Ambrose [51][47]. As an example, the Antoine equation [68] can be used:

$$
\begin{aligned}
& P_{\mathrm{c}}=P_{\mathrm{sat}}\left(T_{\mathrm{c}}\right)=10^{\left[A_{\mathrm{Ant}}+B_{\mathrm{Ant}} /\left(C_{\mathrm{Ant}}+0.1 T_{\mathrm{c}}\right)\right]} \\
& \omega=-\log _{10}\left(\frac{10^{\left[A_{\mathrm{Ant}}+B_{\mathrm{Ant}} /\left(C_{\mathrm{Ant}}+0.7 T_{\mathrm{C}}\right)\right]}}{P_{\mathrm{c}}}\right)-1
\end{aligned}
$$

where $A_{\mathrm{Ant}}, B_{\mathrm{Ant}}$, and $C_{\mathrm{Ant}}$ are the respective Antoine parameters.

Experimental data for the vapor pressure as a function of temperature for the working fluid cyclopentane were taken from the literature [69]. Afterwards a bootstrap method, as described above, was applied: 1) the experimental vapor pressure curve was fitted to an initial set of parameters; 2) new synthetic data sets were generated by random sampling of the errors; and 3) parameter estimation was repeated using each synthetic data set and subsequently $P_{c}$ and $\omega$ were calculated at $T_{c}$. Then $T_{c}$ was perturbed within its stated measurement uncertainty [67]. In order to propagate the measurement errors in temperature to other experimentally measured variables, the Monte Carlo procedure was used. In the Monte Carlo method, 150 random samples from the measurement errors of the temperature were taken and for each sample, variables ( $\left.A_{\text {Ant }}, B_{\text {Ant }}, C_{\text {Ant }}\right)$ were calculated using Eq. (22) and Eq. (23). For the Antoine model, Eq. (23) is usually reliable for $\omega$, but Eq. (22) may not be very good for $P_{c}$. However, for estimating uncertainties both should be adequate.

The uncertainties of $P_{c}$ and $\omega$ are defined as two standard deviations $(2 S D)$ of the distributions obtained by the bootstrap method. This is an engineering standard to account for uncertainty with 95\% confidence. Figure 2 shows the distribution of $T_{c}, P_{c}$, 
and $\omega$ as obtained from the bootstrap method; the forms are similar to normal distributions. A summary of results obtained by the bootstrap method for all of the parameters is given in Table 7. The correlation structure was obtained by calculating the correlation matrix of the errors of $T_{c}, P_{c}$, and $\omega$ (see Table 4). The cubic EoS parameters were highly correlated (i.e. the elements of the correlation matrix were larger than 0.7). The estimated uncertainties in $T_{c}, P_{c}$, and $\omega$ are given in Table 7.

Table 4. Correlation matrix of errors of $T_{c}, P_{c}$, and $\omega$ from the bootstrap method.

\begin{tabular}{c|ccc}
\hline & $T_{c}$ & $P_{c}$ & $\omega$ \\
\hline$T_{c}$ & 1 & & \\
\hline$P_{c}$ & 0.96 & 1 & \\
\hline$\omega$ & -0.93 & -0.85 & 1 \\
\hline
\end{tabular}
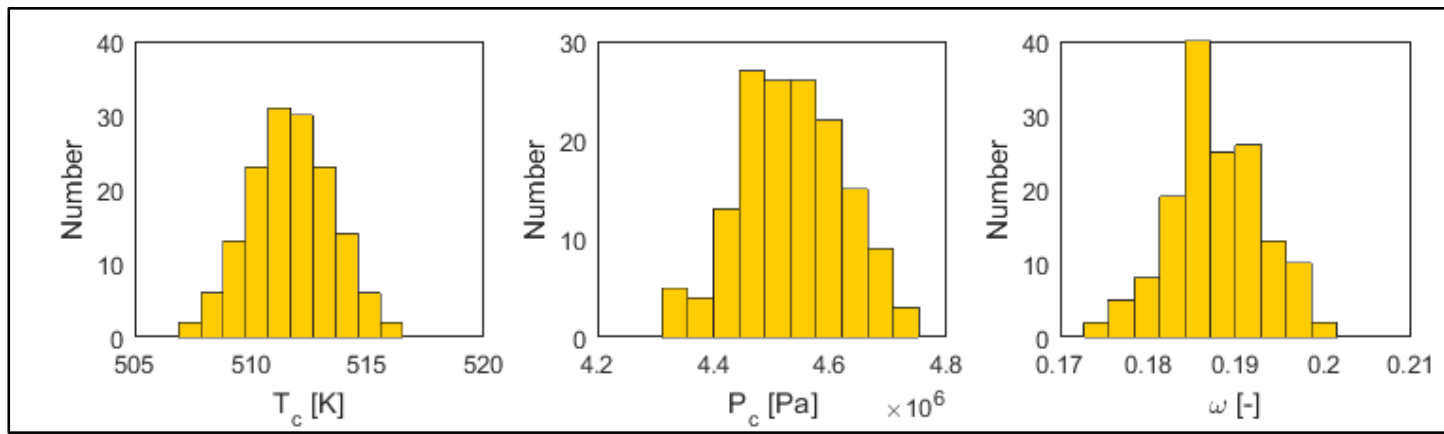

Figure 2. Distribution of SRK parameters from the bootstrap method.

Quantification of uncertainty for parameters of PC-SAFT EoS

The PC-SAFT parameters are usually obtained by fitting residual functions of PC-SAFT [30] to vapor pressure and saturated liquid density data. However, Gross and Sadowski [30] did not report uncertainties of $\sigma, \epsilon / k$ and $m$, for use in our uncertainty propagation analysis.

As a result, we applied the bootstrap method using collected experimental data for vapor pressure [69] over the temperature range of 230-350 K and saturated liquid 
densities [70] for a temperature range of 190-310 K. Following the methodology as outlined above, 1) the experimental data were fitted to the PC-SAFT EoS; 2) new synthetic data sets were obtained; and 3) parameter estimation was repeated (with 150 random samples) using each synthetic data set. The uncertainties of $\sigma$, $\epsilon$, and $m$ were obtained by calculating the standard deviation of the respective distributions, and the correlation structure was calculated through the matrix of errors of $\sigma, \epsilon / k$, and $m$ (see Table 5). The parameters $\epsilon / k$ and $m$ were highly correlated, but $\sigma$ was not strongly correlated with the other parameters. Figure 3 shows the distribution of $\sigma, \epsilon / k$, and $m$ as obtained from the bootstrap method. The distributions are only roughly in normalized form. The estimated uncertainties for $\sigma, \epsilon / k$, and $m$ can be found in Table 7 .

Table 5. Correlation matrix of errors of $\sigma, \epsilon / k$, and $m$ from the bootstrap method.

\begin{tabular}{lccc}
\hline & $\sigma$ & $\epsilon / k$ & $\mathrm{~m}$ \\
\hline$\sigma$ & 1 & & \\
\hline$\epsilon / k$ & 0.05 & 1 & \\
\hline $\mathrm{m}$ & -0.36 & -0.94 & 1 \\
\hline
\end{tabular}
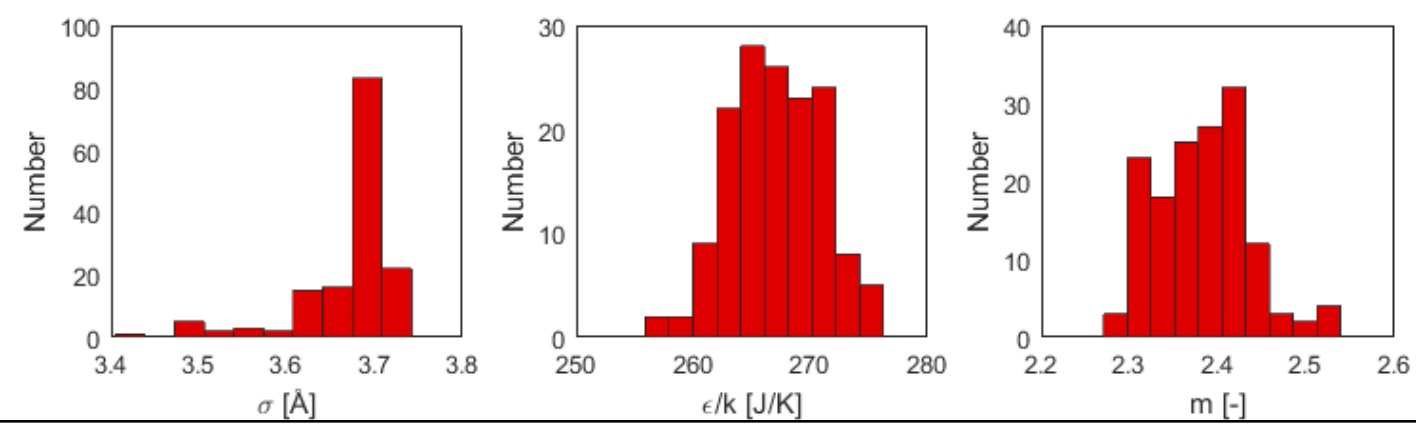

Figure 3. Distribution of PC-SAFT parameters from bootstrap method. 


\section{Quantification of uncertainty for ideal-gas heat capacity parameters}

The bootstrap method was also applied to obtain the uncertainties and the correlation structure of the respective Aly-Lee heat capacity parameters from experimental data [71]. As for the examples above, the standard deviation of the respective bootstrapderived distributions for parameters $A, B, C, D, E$ quantified the uncertainties, and the matrix of errors allowed for the calculation of the correlation structure (see Table 6). With the exception of parameter $B$, all heat capacity parameters were highly correlated with each other. The quantified input uncertainties for $A, B, C, D, E$ can be found in Table 7. Figure 4 shows the distribution of $A, B, C, D, E$ as obtained from the bootstrap method; these are similar to a normalized distribution.

Table 6. Correlation matrix of errors of $A, B, C, D, E$ from the bootstrap method.

\begin{tabular}{cccccc}
\hline & $A$ & $B$ & $C$ & $D$ & $E$ \\
\hline$A$ & 1 & & & & \\
\hline$B$ & 0.28 & 1 & & & \\
\hline$C$ & 0.92 & 0.63 & 1 & & \\
\hline$D$ & 0.96 & 0.51 & 0.99 & 1 & \\
\hline$E$ & 0.99 & 0.40 & 0.96 & 0.99 & 1 \\
\hline
\end{tabular}
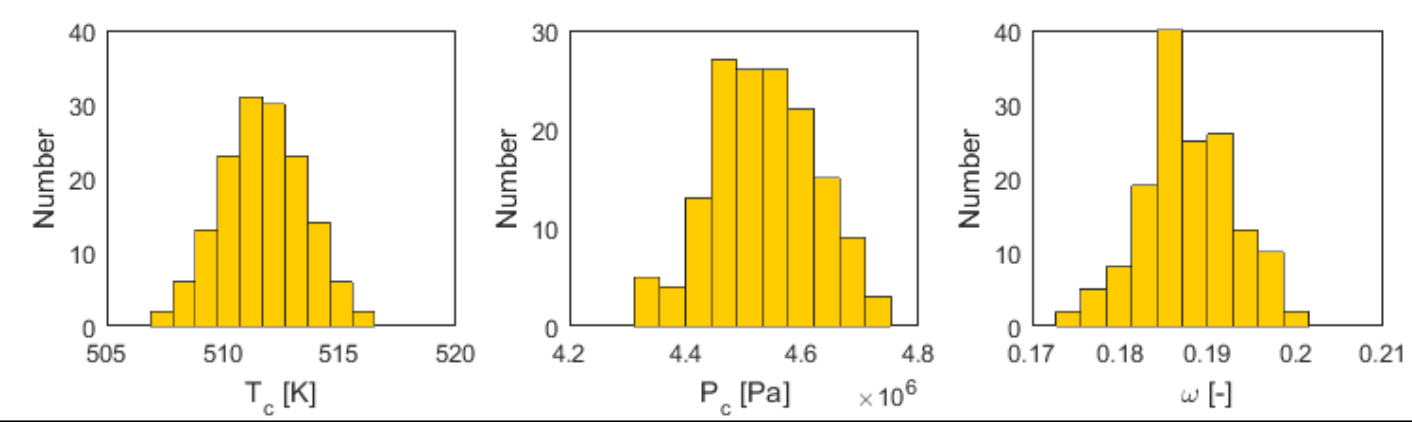

Figure 4. Distribution of heat capacity parameters from the bootstrap method. 
Table 7. Estimated uncertainties for the respective SRK, PC-SAFT, and heat capacity parameters in \%, as calculated from the ratio between calculated two standard deviations $(S D)$ and the actual value from the literature.

\begin{tabular}{|c|c|c|c|c|c|c|}
\hline \multirow{2}{*}{$\begin{array}{l}\text { Uncertainties in } \\
\text { cubic SRK EoS }\end{array}$} & \multicolumn{2}{|c|}{$\frac{2 \cdot S D\left(T_{\mathrm{c}}\right)}{T_{\mathrm{c}}}$} & $\frac{2 \cdot S D\left(P_{\mathrm{c}}\right)}{P_{\mathrm{c}}}$ & \multicolumn{2}{|c|}{$\frac{2 \cdot S D(\omega)}{\omega}$} & Ref. \\
\hline & \multicolumn{2}{|c|}{$0.70 \% *$} & $3.82 \%$ & \multicolumn{2}{|r|}{$5.65 \%$} & [67] \\
\hline \multirow{3}{*}{$\begin{array}{l}\text { Uncertainties in } \\
\text { PC-SAFT EoS }\end{array}$} & \multirow{2}{*}{\multicolumn{2}{|c|}{$\frac{2 \cdot S D(\sigma)}{\sigma}$}} & $2 \cdot S D(\epsilon / k)$ & \multirow{2}{*}{\multicolumn{2}{|c|}{$\frac{2 \cdot S D(m)}{m}$}} & \multirow{2}{*}{ Ref. } \\
\hline & & & $\epsilon / k$ & & & \\
\hline & \multicolumn{2}{|c|}{$3.05 \%$} & $2.89 \%$ & & $4.61 \%$ & [30] \\
\hline \multirow{3}{*}{$\begin{array}{l}\text { Uncertainties in } \\
\text { Aly-Lee heat } \\
\text { capacity model }\end{array}$} & $2 \cdot S D(A)$ & $2 \cdot S D(B)$ & $2 \cdot S D(C)$ & $2 \cdot S D(D)$ & $2 \cdot S D(E)$ & \multirow{2}{*}{ Ref. } \\
\hline & $A$ & $B$ & $C$ & $D$ & $E$ & \\
\hline & $0.34 \%$ & $0.46 \%$ & $0.79 \%$ & $0.61 \%$ & $0.34 \%$ & [55] \\
\hline
\end{tabular}

*directly from experimental measurement uncertainty

\section{Step 4: Monte Carlo procedure for input uncertainty propagation to ORC model output of cubic SRK and PC-SAFT EoS}

A Monte Carlo procedure was used to propagate uncertainties in the fluid-specific EoS parameters to the ORC model output. The procedure follows the work of Frutiger et al. [26] as summarized below.

Specification of fluid property and parameter input uncertainties

The quantified uncertainties of the fluid parameters (from Step 3) serve as input uncertainties to be propagated through the ORC model. We do not intend to improve the accuracy of primary property or parameter data values. On the contrary, we use the reported parameter values of Table 2 together with the estimated uncertainties. 
Sampling of property and parameter search spaces

Sampling is the key step of the Monte Carlo procedure. The Latin Hypercube Sampling method [72] was utilized for probabilistic sampling of 250 values from the fluid property parameter input space of each EoS. The respective uncertainty defined the range of each property parameter. The parameters were assumed to be distributed as found in Step 3. The calculated correlations between the respective parameters were taken into account using the rank-based method for correlation control of Iman and Conover [66]. For the obtained heat capacity constants $(A, B, C, D, E)$, the sampling procedure was performed twice, once with the SRK parameters $\left(T_{c}, P_{c}, \omega\right)$ and a second time with the PC-SAFT parameters $(\sigma, \epsilon / k, m)$.

\section{Evaluation of ORC model for each property and parameter sample}

The ORC model was evaluated for each of the 250 input property parameter samples resulting from Step 4.2. The ORC model simulations for the SRK EoS were carried out as follows:

(1) The sample sets for the heat capacity input A, B, C, D and E (input for the ideal-gas contribution) and the SRK input properties $\left(T_{c}, P_{c}, \omega\right)$ were evaluated together.

(2) The heat capacity parameters were kept constant, while every sample for the SRK input properties was evaluated.

(3) The SRK input properties were kept constant and every sample for the heat capacity input parameters was evaluated.

This procedure was repeated with the samples from the PC-SAFT parameters and the sample set of heat capacity parameters. In this way, it was possible to quantify the influence of the model output uncertainties caused by the ideal-gas and residual functions contributions. Furthermore, the uncertainty propagations of SRK could be directly analyzed, and compared with the ones of PC-SAFT.

Although the error quantification by the bootstrap method and the Monte Carlo procedure were applied only to the SRK and PC-SAFT EoS in this study, the approach 
is completely general, and can be applied to any type of EoS to analyze the propagation of input uncertainty to the output of the EoS model.

The uncertainty analysis was implemented in Matlab (Mathworks, R14) [73]. The software for performing the uncertainty analysis can be provided as m-script files upon request to the corresponding author.

\section{Step 5: Variance-based sensitivity analysis and EoS selection}

The results of the Monte Carlo uncertainty propagations were distributions of the model outputs (e.g. the net power output of the ORC $W_{\mathrm{NET}}$ ). The broader a model output distribution is, the more uncertain is the model output value. The variance of a distribution is a measure of its width and can be used to quantify output uncertainties, subject to the property uncertainties. Given the distribution of a variable from the Monte Carlo sample evaluation, the associated variance of the distribution can be defined. For $W_{\mathrm{NET}}$ this is

$$
V A R\left(W_{\mathrm{NET}}\right)=\frac{1}{n-1} \sum_{i=1}^{n}\left(W_{\mathrm{NET}}(i)-\mu_{W_{\mathrm{NET}}}\right)^{2}
$$

where $W_{\mathrm{NET}}(i)$ is the net power output of one Monte Carlo simulation, $n$ is the number of simulations, and $\mu_{W_{\mathrm{NET}}}$ is the mean value of the distribution, defined as

$$
\mu_{W_{\mathrm{NET}}}=\frac{1}{n} \sum_{i=1}^{n} W_{\mathrm{NET}}(i)
$$

The standard deviation is the square root of the variance,

$$
S D\left(W_{\mathrm{NET}}\right)=\sqrt{V A R\left(W_{\mathrm{NET}}\right)}
$$

To compare the different uncertainty propagations, subject to the EoS parameter uncertainties, a variance-based sensitivity analysis was performed. Sensitivity analysis yields the impact of model parameter uncertainty on the model output uncertainties [74]. 


\section{Step 5.1: Calculation of variance-based sensitivity measures}

The influence of different uncertainty sources on the ORC model outputs may be analyzed by comparing the different variances and standard deviations. As a result, we can compare ideal-gas contributions to uncertainties with those from the nonideal departure functions, and SRK can be considered relative to PC-SAFT. In order to facilitate such comparisons, a sensitivity measure is useful. An example is the sensitivity measure described by Saltelli et al. [75] for the net power output $W_{\text {NFT }}$ of the ORC.

First, we denote the variance of the specific distribution of $W_{\mathrm{NET}}$ that results from only the input uncertainties of the SRK EoS (keeping heat capacity parameters constant) by $V A R\left(W_{\mathrm{NET}}\left(S R K \mid \overline{C_{\mathrm{p}}}\right)\right)$. Then, the variance of the specific distribution of $W_{\mathrm{NET}}$ that results from input uncertainties of both the SRK EoS and the heat capacity parameters is denoted $V A R\left(W_{\mathrm{NET}}\left(S R K, C_{\mathrm{p}}\right)\right)$. The sensitivity measure for SRK input properties, $S_{S R K}$, with respect to the model output uncertainties is then given by

$$
S_{S R K}=\frac{V A R\left(W_{\mathrm{NET}}\left(S R K \mid \overline{C_{\mathrm{p}}}\right)\right)}{V A R\left(W_{\mathrm{NET}}\left(S R K, C_{\mathrm{p}}\right)\right)}
$$

Eq. (27) quantifies the influence of a propagated input property uncertainty of the SRK EoS on the overall propagated uncertainty. Similarly, the sensitivity measure for the influence of other input parameter uncertainties (heat capacity, PC-SAFT parameters) to other ORC model output properties (i.e., enthalpies, entropies, temperatures and pressures at different stages) can be evaluated.

\section{Step 5.2: Analysis and selection of EoS based on uncertainty}

Based on the sensitivity measures and the distributions of the model outputs from the Monte Carlo simulations, we can address the following questions:

(1) Do input uncertainties originating from the ideal-gas contribution or from the departure functions have stronger influence on the model output?

(2) Which of the two departure function input uncertainties (SRK or PC-SAFT) has the stronger effect on the model output? 
(3) Which of the two departure functions (SRK or PC-SAFT) has a lower standard deviation in the ORC model output uncertainty and, consequently, might be preferred from the standpoint of process uncertainty? 


\section{Results and Discussion}

The results are now presented as follows: (1) an overview of the uncertainty analysis results; (2) the sensitivity of the ideal-gas contribution compared to the sensitivity of the departure functions (residual functions); and (3) the uncertainty of SRK compared to that of PC-SAFT.

\section{Overview of the output uncertainties in $\log (P)-h$ and $T$-s diagrams}

The outcome of the Monte Carlo methods is shown on temperature-entropy ( $T$-s) and logarithmic pressure-enthalpy $(\log (P)-h)$ diagrams in Figure 5. The uncertainty is a varying band for both the saturation curves (yellow) and the cycle design (red). All the simulation results obtained from each single property parameter sample are overlaid. The solid black line represents the mean values of the model outputs. From a statistical point of view, the uncertainty bands correspond to the distribution of the model outputs and directly show the sensitivities with respect to the fluid property values. The larger the width of the band, the greater the uncertainty. Hence, Figure 5 gives an overview of all the uncertainty analyses for the SRK EoS (left hand side) and the PC-SAFT EoS (right hand side). These results are analyzed in more detail in the following sections. Figure 5 also gives an overview of the different ORC model outputs that have been further considered for sensitivity analysis in the following results sections (see also Table 8). 


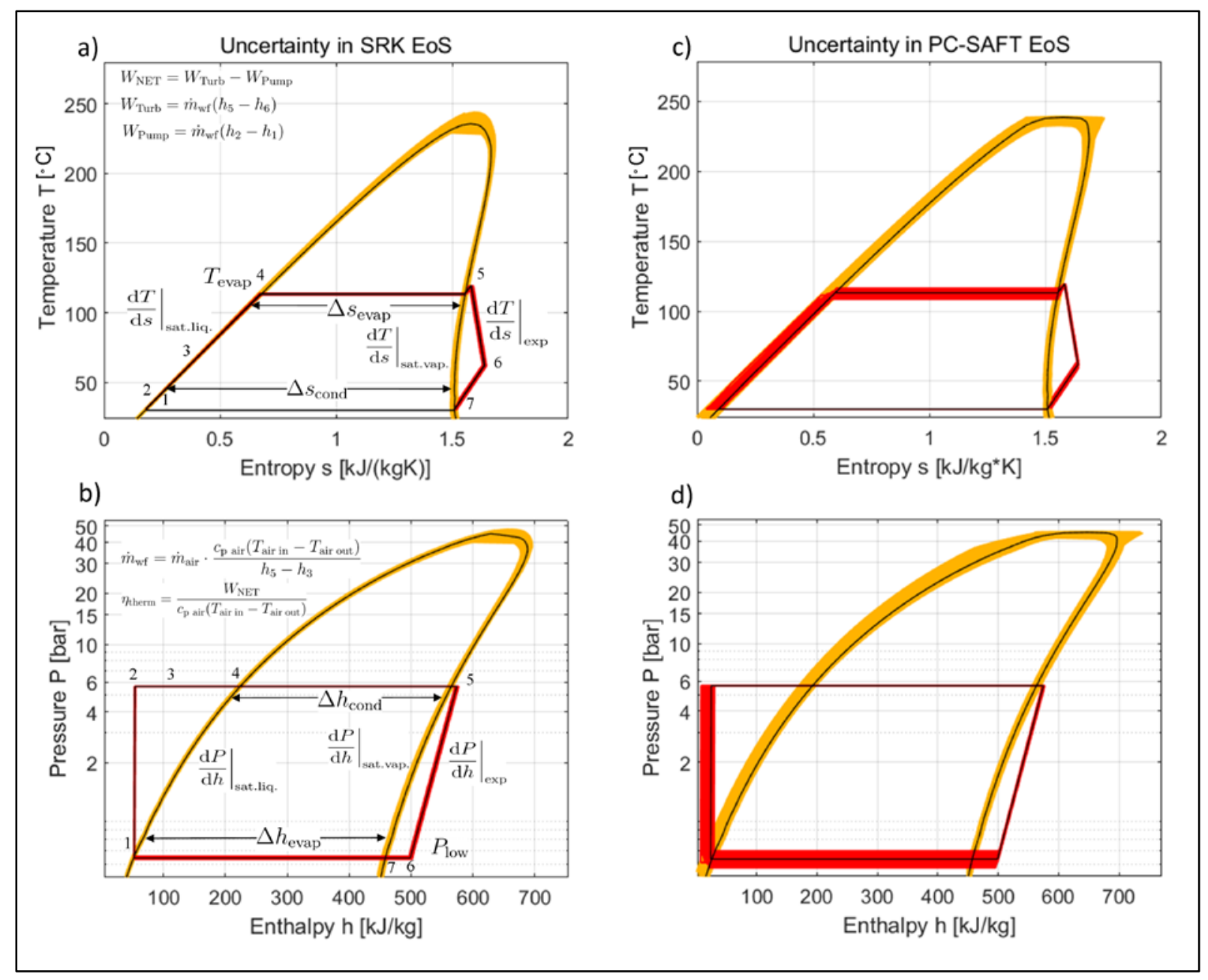

Figure 5. Representation of uncertainty with respect to the fluid properties in the $T$-s diagram and $\log (P)$-h diagram for cyclopentane for SRK and PC-SAFT input uncertainty: Monte Carlo simulations overlaid (yellow/red) and mean (solid black line). The numbers refer to the states of the ORC cycle according to Figure 1. Table 8 lists the symbols for model outputs. 
Table 8. Considered model outputs.

\begin{tabular}{|c|c|}
\hline ORC net power output & $W_{\mathrm{NET}}[\mathrm{kW}]$ \\
\hline Turbine output & $W_{\text {Turb }}[\mathrm{kW}]$ \\
\hline Pump work input & $W_{\text {Pump }}[\mathrm{kW}]$ \\
\hline Thermal efficiency & $\eta_{\text {therm }}[-]$ \\
\hline Mass flow of the working fluid & $\dot{m}_{\mathrm{wf}}\left[\frac{\mathrm{kg}}{\mathrm{s}}\right]$ \\
\hline Evaporation temperature & $T_{\text {evap }}[\mathrm{K}]$ \\
\hline Lower pressure level & $P_{\text {low }}[\mathrm{kPa}]$ \\
\hline Condensation entropy & $\Delta s_{\text {cond }}\left[\frac{\mathrm{kJ}}{\mathrm{kgK}}\right]$ \\
\hline Condensation enthalpy & $\Delta h_{\text {cond }}\left[\frac{\mathrm{kJ}}{\mathrm{kg}}\right]$ \\
\hline Evaporation entropy & $\Delta s_{\text {evap }}\left[\frac{\mathrm{kJ}}{\mathrm{kgK}}\right]$ \\
\hline Evaporation enthalpy & $\Delta h_{\text {evap }}\left[\frac{\mathrm{kJ}}{\mathrm{kgK}}\right]$ \\
\hline $\begin{array}{l}\text { Slope of the expansion line in } \\
\log (P)-h \text { diagram }\end{array}$ & $\left.\frac{\mathrm{d} P}{\mathrm{~d} h}\right|_{\exp }\left[\frac{\mathrm{kPa} \cdot \mathrm{kg}}{\mathrm{kJ}}\right]$ \\
\hline $\begin{array}{l}\text { Slope of the expansion line in } \\
T \text {-s diagram }\end{array}$ & $\left.\frac{\mathrm{d} T}{\mathrm{~d} s}\right|_{\exp }\left[\frac{\mathrm{K}^{2} \cdot \mathrm{kg}}{\mathrm{kJ}}\right]$ \\
\hline $\begin{array}{l}\text { Slope of the saturated vapor } \\
\text { line in } \log (P) \text { - } h \text { diagram }\end{array}$ & $\left.\frac{\mathrm{d} P}{\mathrm{~d} h}\right|_{\text {sat.vap. }}\left[\frac{\mathrm{kPa} \cdot \mathrm{kg}}{\mathrm{kJ}}\right]$ \\
\hline $\begin{array}{l}\text { Slope of the saturated vapor } \\
\text { line in } T \text {-s diagram }\end{array}$ & $\left.\frac{\mathrm{d} T}{\mathrm{~d} s}\right|_{\text {sat.vap. }}\left[\frac{\mathrm{K}^{2} \cdot \mathrm{kg}}{\mathrm{kJ}}\right]$ \\
\hline $\begin{array}{l}\text { Slope of the saturated liquid } \\
\text { line in } \log (P)-h \text { diagram }\end{array}$ & $\left.\frac{\mathrm{d} P}{\mathrm{~d} h}\right|_{\text {sat.liq. }}\left[\frac{\mathrm{kPa} \cdot \mathrm{kg}}{\mathrm{kJ}}\right]$ \\
\hline $\begin{array}{l}\text { Slope of the saturated liquid } \\
\text { line } T \text {-s diagram }\end{array}$ & $\left.\frac{\mathrm{d} T}{\mathrm{~d} s}\right|_{\text {sat.liq. }}\left[\frac{\mathrm{K}^{2} \cdot \mathrm{kg}}{\mathrm{kJ}}\right]$ \\
\hline
\end{tabular}


As shown in Figure 5, the critical regions of the PC-SAFT $\log (P)-h$ and $T$-s diagrams have large uncertainties due to high sensitivity to the EoS parameter uncertainties. However, since our ORC model was operated subcritically, well away from the critical region, poor modelling of the critical region should not affect the ORC model outputs. Although the mean of the saturation line (solid line) was modelled smoothly, parameter uncertainty (orange) caused some outliers of this property.

From the overview figures, it is possible to visually analyze the results of the fluid-specific EoS parameter uncertainty propagation. For example, from the output uncertainty from the SRK EoS shown on the T-s diagram (top of Figure 5), the expansion process uncertainty (states 5 to 6 ) is larger than the uncertainty in the evaporation line (states 4 to 5). This is also shown in the expansion lines and lower pressure line of the $\log (P)$-h diagram (bottom of Figure 5). For the PC-SAFT EoS, a comparatively wide band can be seen for the evaporation temperature (states 2 to 5 ) as well as for the saturated liquid line (states 3 to 4 ) on the $T$-s diagram. Furthermore, the pump (states 1 to 2 ) and the low pressure process have high uncertainty on the $\log (P)-h$ diagram. Note that the uncertainties of PC-SAFT and SRK cannot be compared directly using Figure 5 because the outputs are normalized by the different EoS mass flow rates. A more appropriate comparison of SRK and PC-SAFT EoS is made below.

\section{Ideal-gas contribution versus departure function: Comparison of uncertainty propagation of input uncertainties for cyclopentane}

The effects of the parameter uncertainties on the ideal-gas contribution (i.e., the heat capacity expression) can be compared to those from the departure functions (i.e., SRK and PC-SAFT). Figure 6 shows the output distributions of the ORC net power output $W_{\text {NET }}$ as obtained from the evaluated Monte Carlo samples. The results of the combined uncertainty propagations of the departure functions (SRK and PC-SAFT) and the ideal-gas contributions are shown together with the results from the uncertainty analysis when only the departure functions or the ideal-gas contributions were varied subject to their uncertainties. Figure 6 is divided in two parts: On the left hand side, the propagated input uncertainties of PC-SAFT (red) are compared to the ideal-gas 
contribution, while on the right hand side, results are shown for SRK (yellow) and the ideal gas contribution. The distributions from PC-SAFT and SRK overlap, though the percentage variations can be considered acceptable. However, the mean value of $W_{\mathrm{NET}}$ for the PC-SAFT uncertainty was 2.83 \% higher than for the SRK.

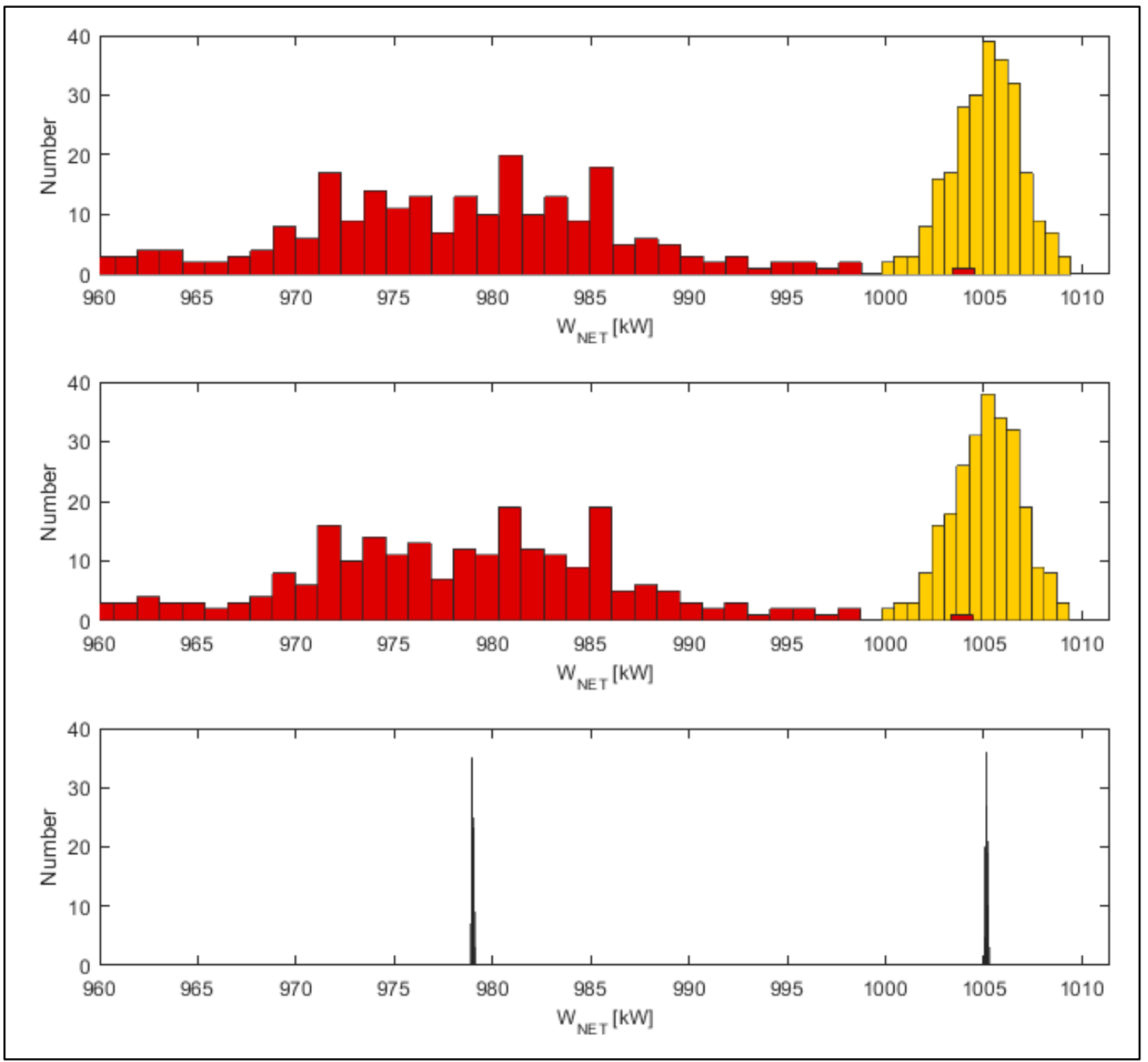

Figure 6. Output distributions of the ORC net power output $W_{\mathrm{NET}}$ from Monte Carlo simulations. Subfigures a, b and c compare the output distributions of the propagated input uncertainties of the departure functions SRK (yellow) and PC-SAFT (red) with the ideal-gas contribution (i.e., from heat capacity parameter uncertainties).

Considering the differences in the widths of the distributions of the net power output $W_{\mathrm{NET}}$ in Figure 6 , the influence of the propagated heat capacity uncertainties on the 
model output was small compared to the effect of the uncertainties in the departure functions for both SRK and PC-SAFT. The mean of the thermal efficiency of the ORC $\eta_{\text {therm }}$ was $15.05 \%$ for SRK and $14.63 \%$ for PC-SAFT. Hence, it should be noted that the ORC model outputs obtained whith PC-SAFT and SRK do not differ strongly.

Leekumjorn et al. [76] thoroughly analyzed the relative errors of both PC-SAFT and SRK compared to experimental values of vapor pressures as functions of temperatures. These authors showed deviations of 2-6 \% for a variety of hydrocarbon fluids.

The uncertainty analysis results for other ORC model outputs were analyzed by their respective sensitivity measures, taking into account that the ORC model and the EoS were highly non-linear and the different fluid properties and parameters could potentially influence every model output. Figures 7 (SRK) and 8 (PC-SAFT) give an overview of the results of the uncertainty analysis of all the output variables considered. The sensitivity measures of the input uncertainties from the heat capacity correlation are plotted together with those from the SRK and PC-SAFT EoS.

As Figures 7 and 8 show, the two sensitivities for ideal and nonideal gas contributions sum to unity, because these are additive in the enthalpy and entropy calculations [75].

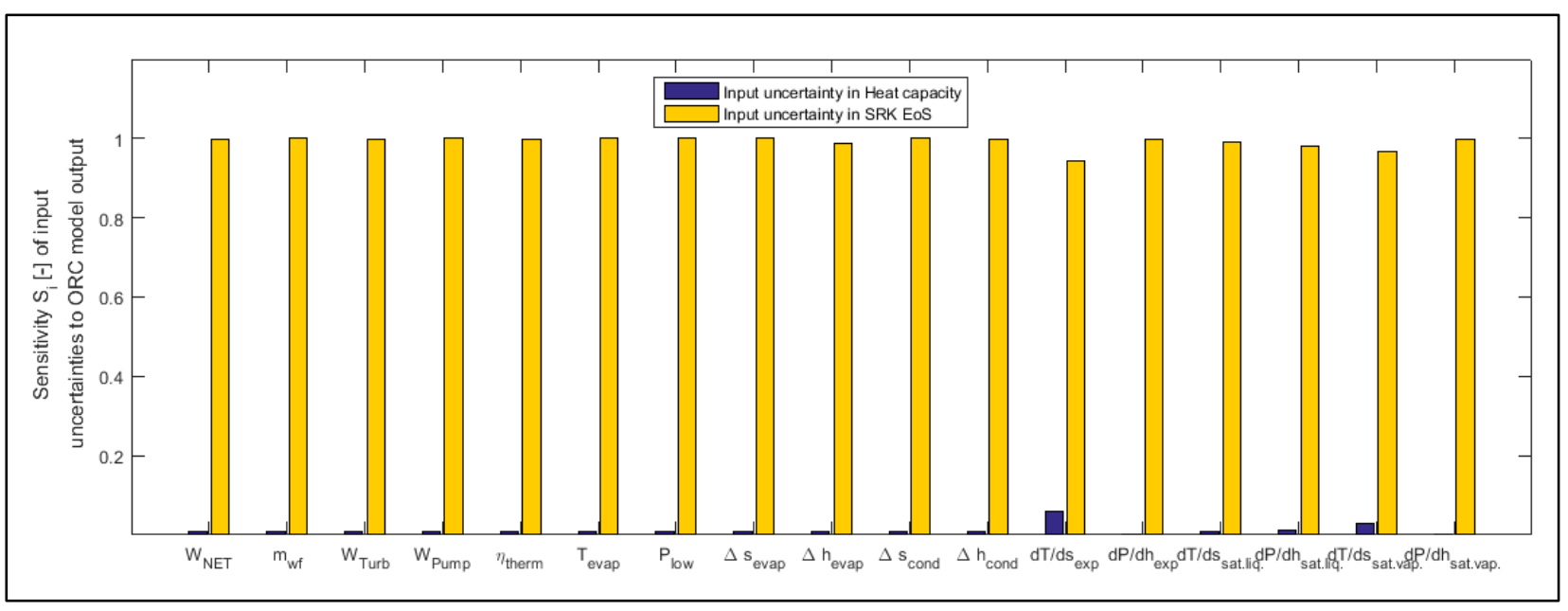

Figure 7. Sensitivity measures $S_{i}$ for influence of propagated heat capacity parameter uncertainties as well as SRK EoS input uncertainties on the respective model outputs (see also Table 8). 


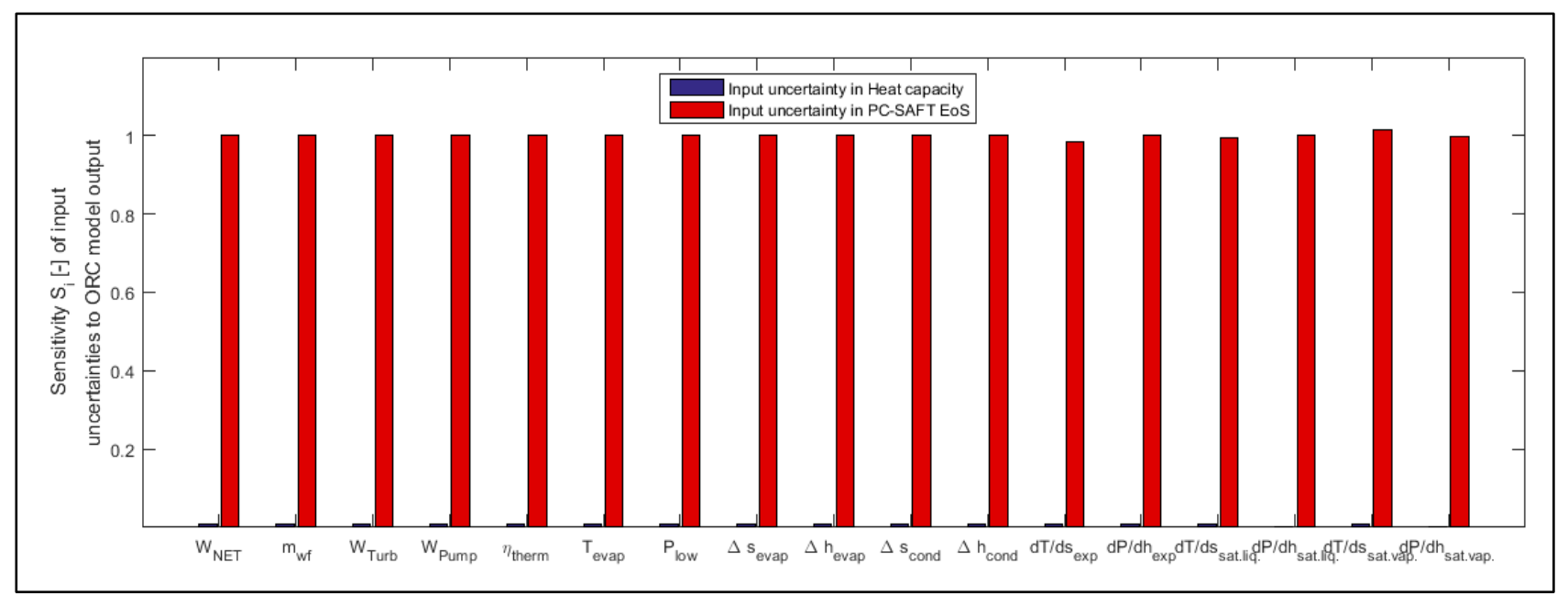

Figure 8. Sensitivity measures $S_{i}$ for influence of propagated heat capacity parameter uncertainties as well as PC-SAFT EoS input uncertainties on the respective model outputs (see also Table 8).

Sensitivity of the departure functions of SRK and PC-SAFT was much larger than that of the ideal-gas contribution for all the output variables. This is expected since in the ORC both gas and liquid states exist at high pressures. Therefore, the real-gas deviation from the ideal-gas becomes important. Small changes in the ideal-gas enthalpy or entropy contribution do not affect the system strongly, whereas changes of the departure functions will.

There are studies in the literature suggesting that the heat capacity correlation can strongly affect cycle performance [77]. Here, the Aly-Lee heat capacity correlation fitted the experimental data very well over the given temperature range, leading to small uncertainties in the heat capacity parameters (as estimated by the bootstrap method). In addition, the correlation structure was retained. This prevented overestimation of the corresponding uncertainty. The uncertainty in the heat capacity itself was very low $(<1$ \% uncertainty), which propagates to a small uncertainty in the ideal-gas contribution. 


\section{SRK versus PC-SAFT: Comparison of input uncertainties propagation of and selection of EoS for cyclopentane}

In step 1 of Methods and Tools, we compared the accuracy of the two EoS, looking at the differences of experimental and predicted data. The PC-SAFT EoS had an average relative error of $0.05 \%$, while the SRK EoS had $0.20 \%$. Hence, the accuracy of PCSAFT was superior.

As an additional tool, the SRK and PC-SAFT EoS can be compared in terms of input uncertainty propagation to the ORC model outputs by analyzing the standard deviations of the model output distributions (e.g. the distribution of $W_{\mathrm{NET}}$ in Figure 6). The standard deviations of the ORC model output distributions for the different ORC model outputs are shown in Figures 9 and 10. Unlike the section before, the sensitivity measure could not be used for the comparison, because the two EoS did not have the same reference variance. Instead the standard deviations of the respective output distributions have been compared. 


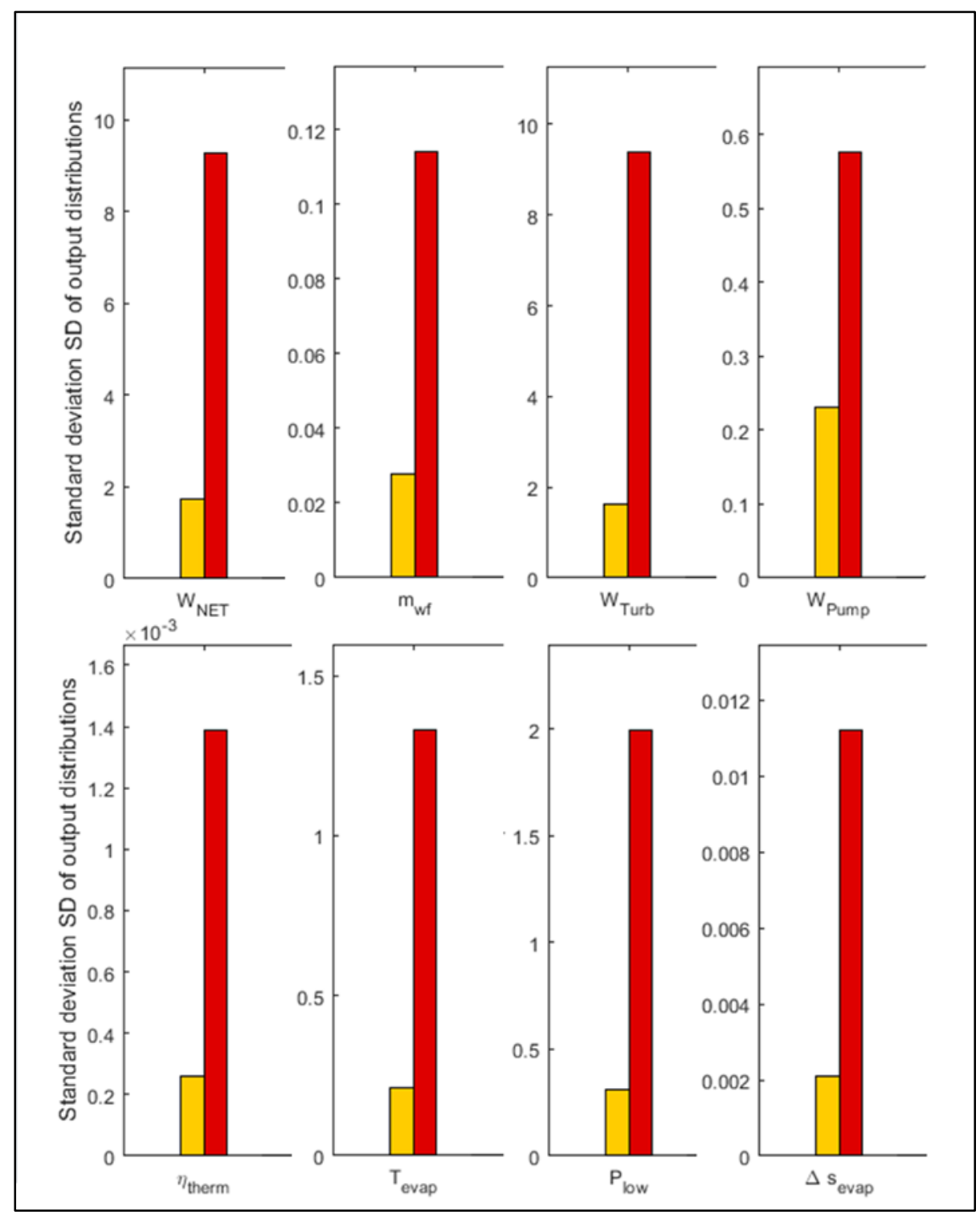

Figure 9. Standard deviations $S D$ of the different ORC model output distributions obtained from propagating input parameter uncertainties for SRK (yellow) and input parameters of PC-SAFT (red) (see also Table 8). 


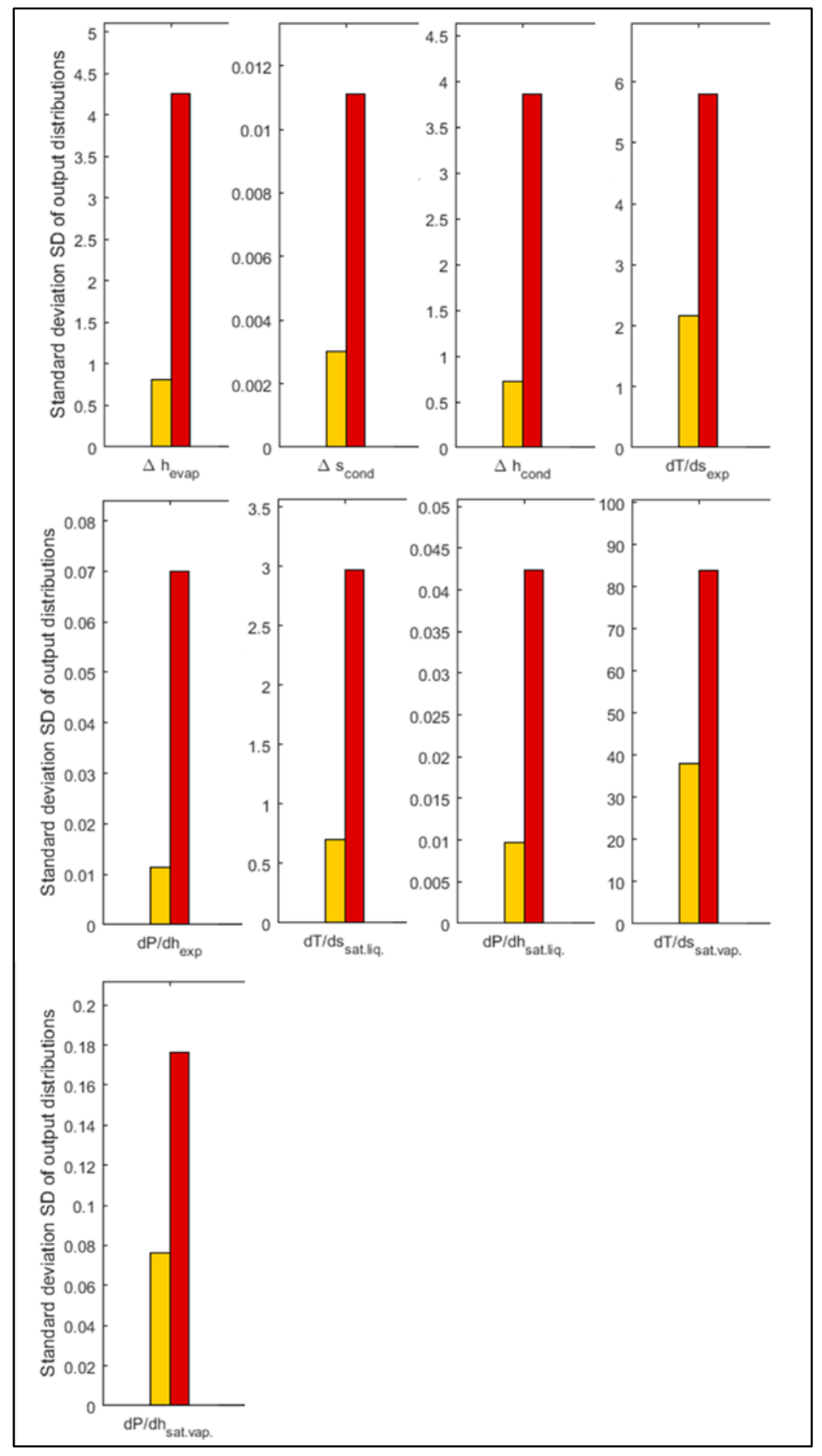

Figure 10. Standard deviations $S D$ of the different ORC model output distributions obtained from propagating input parameter uncertainties for SRK (yellow) and input parameters of PC-SAFT (red) (see also Table 8). 
The standard deviations of the model output distributions are larger for PCSAFT. This can also be seen from the width of the distributions of the net power output in Figure 6, which are much larger for PC-SAFT than SRK. However, the parameter uncertainties of SRK and PC-SAFT were similar (see Table 7). Even small uncertainties in the PC-SAFT parameters apparently lead to relatively large output standard deviations, at least compared to the SRK. The uncertainty analysis shows that the uncertainties in the PC-SAFT parameters interact more strongly than do those of the SRK, leading to a higher output uncertainty. The cause of this could be the differences in mathematical form, or the different data used to obtain the parameters, or both. The PC-SAFT parameters enter into several different functions, which are (from a model point of view) highly nested and often of contrasting effects whereas the SRK parameterization is more direct. In addition, many temperature-dependent data were used to obtain the PC-SAFT parameters while only constant critical property data were used for SRK. Given that the effects are lumped together, it is not possible to separate them. We note that Peng-Robinson cubic EoS gives very similar results to the SRK when put through the same analysis [76]. The difference between them for $W_{\mathrm{NET}}$ was only $0.54 \%$.

The Monte Carlo uncertainty analysis used here can be used as an additional criterion to justify the choice of an EoS (in addition to accuracy and computational efficiency). Lower output uncertainties would be desirable from a modeling point of view because the results are expected to be more reliable, especially over extended ranges of conditions. Considering the used experimental data of the thermo-physical properties (i.e. vapour pressure), the SRK EoS is slightly less accurate than PC-SAFT in predicting properties. However, for the present ORC model and working fluid (cyclopentane), one needs to have experimental evaluation of the proposed ORC process design and measure the power output $\left(W_{\mathrm{NET}}\right)$ in order to calculate the accuracy of the two candidate models: namely ORC model including SRK versus ORC model including PC-SAFT. Such experimental data for ideally more than one working fluid candidates will enable statistical evaluation of accuracy of both models for ORC process design. In the absence of such experimental data, one has the model output uncertainty for both models to work with. As demonstrated in Frutiger et al. [26], the uncertainty in 
the predicted power output can be used cautiously or optimistically when searching for alternative candidates. 


\section{Conclusions}

Uncertainties of EoS can be analyzed as an additional, complementary tool to EoS accuracy also in situations where experimental data are not available to calculate accuracy. This study developed parameter uncertainties for two types of equations of state (SRK and PC-SAFT) from measured data using a bootstrap method. These EoS parameter uncertainties were propagated via a Monte Carlo procedure to the output of an organic Rankine cycle model for power production via waste heat recovery from the exhaust gas of a marine diesel engine. Variance-based sensitivity analysis allowed for the comparison of the different outcomes of the uncertainty analyses.

It was found that:

- The bootstrap method allowed for the quantification of the uncertainties of the fluid-specific parameters of both EoS, including their corresponding correlation structure, from experimental data.

- The propagated output uncertainties of the ORC model were determined more by uncertainties in the EoS departure functions than uncertainties from the idealgas contribution from the heat capacity model.

- The PC-SAFT EoS had an average relative error between experimental and predicted vapor pressure data of $0.05 \%$, while SRK had an error of $0.20 \%$. This suggests that the PC-SAFT EoS seems more accurate. However, this is not unexpected, since PC-SAFT was fitted to a wide range of vapor pressure data on cyclopentane, while SRK was not.

- The range of the ORC model output uncertainties (i.e. the standard deviations of the respective distributions) were smaller for SRK than for PC-SAFT, indicating that, from an uncertainty point of view, the SRK EoS could be preferable for this application, i.e. performance evaluation of working fluid in ORC process design. It cannot be determined if the higher uncertainty of PC-SAFT is due to differences in data for parameter estimation or in the mathematical forms of the EoS. One needs to have experimental evaluation of the proposed ORC process design and measure the power output $\left(W_{\mathrm{NET}}\right)$ in order to calculate the accuracy of the two candidate models. At this stage, given that the distribution of 
uncertainties of PC-SAFT is much broader than that from the SRK, while the property accuracy is not dramatically different, SRK seems preferable.

We suggest that future process modelling studies should examine uncertainty as well as accuracy of potential EoS models in order to gain additional insights about uncertainties in fluid properties, parameters, and EoS model structure. In particular, measurement errors in data should be taken into account when developing and reporting EoS models and the resulting covariance matrix of model parameters should be calculated and reported. This allows direct propagation of parameter uncertainties to model output uncertainties, which provides another and important criterion for property model selection for process design. 


\section{References}

[1] Bühler F, Fridolin M, Huang B, Andreasen JG, Elmegaard B. Mapping of low temperature heat sources in Denmark. ECOS 2015 28th Int Conf Effic Cost, Optim Simul Environ Impact Energy Syst 2015.

[2] Invernizzi CM. The Organic Rankine Cycle. Closed Power Cycles, Thermodyn. Fundam. Appl., London: Springer Verlang; 2013, p. 117-76.

[3] Lai NA, Wendland M, Fischer J. Working fluids for high-temperature organic Rankine cycles. Energy 2011;36:199-211. doi:10.1016/j.energy.2010.10.051.

[4] Papadopoulos AI, Stijepovic M, Linke P. On the systematic design and selection of optimal working fluids for Organic Rankine Cycles. Appl Therm Eng 2010;30:760-9.

[5] Bao J, Zhao L. A review of working fluid and expander selections for organic Rankine cycle. Renew Sustain Energy Rev 2013;24:325-42.

[6] Linke P, Papadopoulos A, Seferlis P. Systematic Methods for Working Fluid Selection and the Design, Integration and Control of Organic Rankine Cycles-A Review. Energies 2015;8:4755-801.

[7] Lemmon E, Huber M, McLinden M. Reference fluid thermodynamic and transport properties-REFPROP, standard reference database 23, version 8.0, National Institute of Standard and Technology; 2007.

[8] Bell I, Wronski J, Quoilin S, Lemort V. Pure and pseudo-pure fluid thermophysical property evaluation and the open-source thermophysical property library CoolProp. Ind Eng Chem Res 2014;53:2498-508.

[9] Wang EH, Zhang HG, Fan BY, Ouyang MG, Zhao Y, Mu QH. Study of working fluid selection of organic Rankine cycle (ORC) for engine waste heat recovery. Energy 2011;36:3406-18. doi:10.1016/j.energy.2011.03.041.

[10] Chys M, Broek M Van Den, Vanslambrouck B, Paepe M De. Potential of zeotropic mixtures as working fl uids in organic Rankine cycles. Energy 2012;44:623-32.

[11] Andreasen JG, Larsen U, Knudsen T, Pierobon L, Haglind F. Selection and optimization of pure and mixed working fluids for low grade heat utilization using organic rankine cycles. Energy 2014;73:204-13.

[12] Zhai H, Shi L, An Q. Influence of working fluid properties on system performance and screen evaluation indicators for geothermal ORC (organic Rankine cycle) system. Energy 2014;74:2-11.

[13] Luo D, Mahmoud A, Cogswell F. Evaluation of Low-GWP fluids for power generation with Organic Rankine Cycle. Energy 2015;85:481-8. doi:10.1016/j.energy.2015.03.109.

[14] Rödder M, Neef M, Laux C, Priebe KP. Systematic fluid selection for organic Rankine cycles (ORC) and performance analysis for a combined high and temperature low temperature cycle. Proc ASME Turbo Expo 2015 Turbine Tech 
Conf Expo 2015;138:1-9.

[15] Hærvig J, Sørensen K, Condra TJ. Guidelines for optimal selection of working fluid for an organic Rankine cycle in relation to waste heat recovery. Energy 2016;96:592-602.

[16] Xu J, Yu C. Critical temperature criterion for selection of working fluids for subcritical pressure Organic Rankine cycles. Energy 2014;74:719-33.

[17] Regulation (EC) No 1005/2009 of the European Parliament and of the council. Off J Eur Communities 2000;L 269:1-15.

[18] McLinden MO, Kazakov AF, Steven Brown J, Domanski PA. A thermodynamic analysis of refrigerants: Possibilities and tradeoffs for Low-GWP refrigerants. Int J Refrig 2014;38:80-92. doi:10.1016/j.ijrefrig.2013.09.032.

[19] Peng D-Y, Robinson DB. A New Two-Constant Equation of State. Ind Eng Chem Fundam 1976;15:59-64.

[20] Soave G. Equilibrium constants from a modified Redlich-Kwong equation of state. Chem Eng Sci 1972;27:1197-203. doi:10.1016/0009-2509(72)80096-4.

[21] Holderbaum T, Gmehling J. PSRK: A Group Contribution Equation of State Based on UNIFAC. Fluid Phase Equilib 1991;70:251-65. doi:10.1016/03783812(91)85038-V.

[22] Papadopoulos AI, Stijepovic M, Linke P, Seferlis P, Voutetakis S. Toward Optimum Working Fluid Mixtures for Organic Rankine Cycles using Molecular Design and Sensitivity Analysis. Ind Eng Chem Res 2013;52:12116-33.

[23] Drescher U, Brüggemann D. Fluid selection for the Organic Rankine Cycle (ORC) in biomass power and heat plants. Appl Therm Eng 2007;27:223-8.

[24] Brown JS, Brignoli R, Daubman S. Methodology for estimating thermodynamic parameters and performance of working fluids for organic Rankine cycles. Energy 2014;73:818-28.

[25] Liu W, Meinel D, Wieland C, Spliethoff H. Investigation of hydrofluoroolefins as potential working fluids in organic Rankine cycle for geothermal power generation. Energy 2014;67:106-16.

[26] Frutiger J, Andreasen JG, Liu W, Spliethoff H, Haglind F, Abildskov J, et al. Working fluid selection for organic Rankine cycles - impact of uncertainty of fluid properties. Energy 2016;109:987-97.

[27] Roskosch D, Atakan B. Reverse engineering of fluid selection for thermodynamic cycles with cubic equations of state, using a compression heat pump as example. Energy 2015;81:202-12. doi:10.1016/j.energy.2014.12.025.

[28] Sánchez D, Monje Brenes B, Muñoz de Escalona, José M. Chacartegui R. Nonconventional combined cycle for intermediate temperature systems. Int J Energy Res 2013;37:403-11.

[29] Molina-Thierry DP, Flores-Tlacuahuac A. Simultaneous optimal design of 
organic mixtures and rankine cycles for low-temperature energy recovery. Ind Eng Chem Res 2015;54:3367-83.

[30] Gross J, Sadowski G. Perturbed-Chain SAFT: An Equation of State Based on a Perturbation Theory for Chain Molecules. Ind Eng Chem Res 2001;40:1244-60. doi:10.1021/ie0003887.

[31] Lai NA, Wendland M, Fischer J. Description of linear siloxanes with PC-SAFT equation. Fluid Phase Equilib 2009;283:22-30. doi:10.1016/j.fluid.2009.05.011.

[32] Oyewunmi OA, Taleb AI, Haslam AJ, Markides CN. An assessment of workingfluid mixtures using SAFT-VR Mie for use in organic Rankine cycle systems for waste-heat recovery. Comput Therm Sci 2014;6:301-16.

[33] Lampe M, Stavrou M, Bücker HM, Gross J, Bardow A. Simultaneous Optimization of Working Fluid and Process for Organic Rankine Cycles Using PC-SAFT. Ind Eng Chem Res 2014;53:8821-30. doi:10.1021/ie5006542.

[34] Saleh B, Koglbauer G, Wendland M, Fischer J. Working fluids for lowtemperature organic Rankine cycles. Energy 2007;32:1210-21.

[35] Leck T. Evaluation of HFO-1234yf as a Potential Replacement for R-134a in Refrigeration Applications. Proc 3rd IIR Conf Thermophys Prop ... 2009;155:19.

[36] Akasaka R, Tanaka K, Higashi Y. Thermodynamic property modeling for 2,3,3,3-tetrafluoropropene (HFO-1234yf). Int $\mathrm{J}$ Refrig 2010;33:52-60. doi:10.1016/j.ijrefrig.2009.09.004.

[37] Span R. Multiparameter Equations of State. 2000.

[38] Kumar SK, Kurz R, O’Connell JP. Equations of state for gas compressor design and testing. ASME 1999 Int Gas Turbine Aeroengine Congr Exhib 1999;2:1-10.

[39] Wagner W, Setz U. A new equation of state and tables of thermodynamic properties for methane covering the range from melting line to $625 \mathrm{~K}$ at pressures up to 1000 Mpa. J Phys Chem Ref Data 1991;20:1061-155.

[40] Dong Q, Chirico RD, Yan X, Hong X, Frenkel M. Uncertainty Reporting for Experimental Thermodynamic Properties. J Chem Eng Data 2005;50:546-50.

[41] Hukkerikar AS, Sarup B, Ten Kate A, Abildskov J, Sin G, Gani R. Groupcontribution $+(\mathrm{GC}+)$ based estimation of properties of pure components: Improved property estimation and uncertainty analysis. Fluid Phase Equilib 2012;321:25-43.

[42] Sin G, Gernaey K V., Eliasson Lantz A. Good Modeling Practice for PAT Applications: Propagation of Input Uncertainty and Sensitivity Analysis. Biotechnol Prog 2009;25:1043-53.

[43] Feistel R, Lovell-Smith JW, Saunders P, Seitz S. Uncertainty of empirical correlation equations. Metrologia 2016;53:1079-90. doi:10.1088/0026$1394 / 53 / 4 / 1079$. 
[44] Bell I, Jäger A. Helmholtz energy transformation of common cubic equations of state for use with pure fluids and mixtures. J Res Natl Inst Stand Technol 2016;121:238-63.

[45] Kontogeorgis GM, Folas GK. Industrial Applications Thermodynamic Models for Industrial Applications From Classical and Advanced. West Sussex, UK: John Wiley \& Son; 2010.

[46] Redlich O, Kwong JNS. On the thermodynamics of solutions; an equation of state; fugacities of gaseous solutions. Chem Rev 1949;44:233-44. doi:10.1021/cr60137a013.

[47] Poling BE, Prausnitz JM, O’Connell JP. The Estimation of Physical Properties. Prop. Gases Liq., New York: McGraw-Hill; 2004, p. 1-9.

[48] Economou IG. Statistical Associating Fluid Theory: A Successful Model for the Calculation of Thermodynamic and Phase Equilibrium Properties of Complex Fluid Mixtures. Ind Eng Chem Res 2002;41:953-62. doi:10.1021/ie0102201.

[49] Barker JA, Henderson D. Perturbation theory and equation of state for fluids: the square well potential. J Chem Phys 1967;47:2856-61. doi:10.1063/1.1701689.

[50] Fakouri Baygi S, Pahlavanzadeh H. Application of the perturbed chain-SAFT equation of state for modeling $\mathrm{CO} 2$ solubility in aqueous monoethanolamine solutions. Chem Eng Res Des 2015;93:789-99. doi:10.1016/j.cherd.2014.07.017.

[51] Ambrose D, Patel NC. The correlation pressures and estimation of vapour IV. Extrapolation of vapour pressures and estimation of critical pressures the principle of corresponding states using two reference fluids with non-spherical molecules. J Chem Thermodyn 1984;16:459-68.

[52] Aly F, Lee L. Self-consistent equations for calculating heat capacity, enthalpy, and entropy the ideal gas. Fluid Phase Equilib 1981;6:169-79.

[53] Frenkel M, Chirico RD, Diky V, Yan X, Dong Q, Muzny C. ThermoData Engine (TDE): Software Implementation of the Dynamic Data Evaluation Concept. J Chem Inf Model 2005;45:816-38.

[54] Diky V, Chirico RD, Muzny CD, Kazakov AF, Kroenlein K, Magee JW, et al. ThermoData Engine (TDE): Software Implementation of the Dynamic Data Evaluation Concept. 8. Properties of Material Streams and Solvent Design. Chem Inf Model 2013;53:249-66. doi:10.1021/ci300470t.

[55] R. L. Rowley, W. V. Wilding, J. L. Oscarson, T. A. Knotts, N. F. Giles, DIPPR ${ }^{\circledR}$ Data Compilation of Pure Chemical Properties, Design Institute for Physical Properties, AIChE, New York, NY 2014.

[56] Hwang Y, Ohadi M, Radermacher R. Natural refrigerants. Mech Eng 1998;120:96-9.

[57] Gedanitz H, Davila MJ, Lemmon EW. Speed of sound measurements and a fundamental equation of state for cyclopentane. J Chem Eng Data 2015;60:13317. doi:10.1021/je5010164. 
[58] Larsen U, Pierobon L, Haglind F, Gabrielii C. Design and optimisation of organic Rankine cycles for waste heat recovery in marine applications using the principles of natural selection. Energy 2013;55:803-12.

[59] Andreasen JG, Larsen U, Knudsen T, Pierobon L, Haglind F. Selection and optimization of pure and mixed working fluids for low grade heat utilization using organic Rankine cycles. Energy 2014;73:204-13.

[60] MAN Diesel \& Turbo. Waste Heat Recovery System (WHRS) for Reduction of Fuel Consumption, Emission and EEDI. 2012. doi:5510-0136-03ppr.

[61] MAN Diesel and Turbo: CEAS Engine Data report 7G95ME-C9.5 with LP SCR \& EGB Specified main engine and other parameters. 2016.

[62] Kennedy J. Particle swarm optimization. Encycl Mach Learn 2010;46:685-91. doi:10.1109/ICNN.1995.488968.

[63] Efron B. Bootstrap methods: another look at the jackknife. Ann Stat 1979;7:126.

[64] Seber G, Wild C. Nonlinear Regression. Hoboken, NJ, USA: John Wiley \& Sons, Inc.; 1989.

[65] Frutiger J, Marcarie C, Abildskov J, Sin G. A comprehensive methodology for development, parameter estimation, and uncertainty analysis of group contribution based property models - an application to heat of combustion. J Chem Eng Data 2016;61:602-13.

[66] Iman R, Conover W. A distribution-free approach to inducing rank correlation among input variables. Commun Stat Part B-Simulation Comput 1982;11:31134.

[67] Daubert TE. Vapor - Liquid Critical Properties of Elements and Compounds . 5. Branched Alkanes and Cycloalkanes. J Chem Eng Data 1996;41:365-72.

[68] Aston JG, Fink HL, Schumann SC. The Heat Capacity and Entropy, Heats of Transition, Fusion and Vaporization and the Vapor Pressures of Cyclopentane. Evidence for a Non-planar Structure. J Am Chem Soc 1943;65:341-6.

[69] Mokbel I, Rauzy E, H. L, C. B, J. J. Vapor pressures of 12 alkylcyclohexanes, cyclopentane, butylcyclopentane and trans-decahydronaphthalene down to 0.5 Pa. Experimental results, correlation and prediction by an equation of state. Fluid Phase Equilib 1995;108:103-20.

[70] Garcia Baonza V, Caceres Alonso M, Nunez Delgado J. Study of the Equation of State of Cyclopentane from 193 to $298 \mathrm{~K}$ and Pressures up to 104 MPa. J Phys Chem 1992;96:1859-68.

[71] McCullough JP, Pennington RE, Smith JC, Hossenlopp IA, Waddington G. Thermodynamics of Cyclopentane, Methylcyclopentane and 1 ,cis-3Dimethylcyclopentane: Verification of the Concept of Pseudorotation. J Am Chem Soc 1959;81:5880-3. 
[72] Helton JC, Davis FJ. Latin hypercube sampling and the propagation of uncertainty in analyses of complex systems. Reliab Eng Syst Saf 2003;81:23-69.

[73] MATLAB 2015b, The MathWorks, Inc., Natick, Massachusetts, United States n.d.

[74] Saltelli A, Sobol IM. About the use of rank transformation in sensitivity analysis of model output. Reliab Eng Syst Saf 1995;50:225-39.

[75] Saltelli A, Annoni P, Azzini I, Campolongo F, Ratto M, Tarantola S. Variance based sensitivity analysis of model output. Design and estimator for the total sensitivity index. Comput Phys Commun 2010;181:259-70. doi:10.1016/j.cpc.2009.09.018.

[76] Leekumjorn S, Krejbjerg K. Phase behavior of reservoir fluids: Comparisons of PC-SAFT and cubic EOS simulations. Fluid Phase Equilib 2013;359:17-23. doi:10.1016/j.fluid.2013.07.007.

[77] Stijepovic MZ, Linke P, Papadopoulos AI, Grujic AS. On the role of working fluid properties in Organic Rankine Cycle performance. Appl Therm Eng 2012;36:406-13. doi:10.1016/j.applthermaleng.2011.10.057. 